This document is the accepted manuscript version of the following article: Geitner, N. K., Ogilvie Hendren, C., Cornelis, G., Kaegi, R., Lead, J. R., Lowry, G. V., ... Wiesner, M. R. (2020). Harmonizing across environmental nanomaterial testing media for increased comparability of nanomaterial datasets. Environmental Science: Nano, 7(1), 13-36. https://doi.org/10.1039/c9en00448c

\title{
Harmonizing Across Environmental Nanomaterial Testing Media for Increased Comparability of Nanomaterial Datasets
}

Nicholas K Geitner, ${ }^{\text {ab }}$ Christine Ogilvie Hendren, ${ }^{\text {ab }}$ Geert Cornelis, ${ }^{\mathrm{c}}$ Ralf Kaegi, ${ }^{\mathrm{d}}$ Jamie Lead, ${ }^{\text {ef }}$ Gregory Lowry, ${ }^{\mathrm{bg}}$ Iseult Lynch, ${ }^{\mathrm{h}}$ Bernd Nowack, ${ }^{\mathrm{i}}$ Elijah Petersen, ${ }^{\mathrm{j}}$ Emily Bernhardt, ${ }^{\mathrm{bk}}$ Scott Brown, ${ }^{1}$ Warren Chan, ${ }^{\mathrm{m}}$ Camille de Garidel-Thoron, ${ }^{\mathrm{n}}$ Jaydee Hanson, ${ }^{\mathrm{o}}$ Stacey Harper, ${ }^{\mathrm{p}}$ Kim Jones, ${ }^{\text {bq }}$ Frank von der Kammer, ${ }^{\mathrm{r}}$ Alan Kennedy, ${ }^{\mathrm{s}}$ Justin Kidd, ${ }^{\mathrm{t}}$ Cole Matson, ${ }^{\text {bu }}$ Christopher Metcalf, ${ }^{\mathrm{v}}$ Joel Pedersen, ${ }^{\mathrm{w}}$ Willie J G M Peijnenburg, ${ }^{\mathrm{x}}$ Joris T K Quik, ${ }^{\mathrm{y}}$ Sónia M Rodrigues, ${ }^{\mathrm{z}}$ Jerome Rose ${ }^{\dagger}$ Phil Sayre, ${ }^{\ddagger}$ Marie Simonin, ${ }^{b k}$ Claus Svendsen, ${ }^{\S}$ Robert Tanguay, ${ }^{\text {Il }}$ Nathalie Tefenkji, ${ }^{1}$ Tom van Teunenbroek,${ }^{2}$ Gregory Thies, ${ }^{3}$ Yuan Tian, ${ }^{\text {ab }}$ Jacelyn Rice, ${ }^{\text {ab }}$ Amalia Turner, ${ }^{\mathrm{ab}}$ Jie Liu, ${ }^{\mathrm{b} 4}$ Jason Unrine, ${ }^{\mathrm{b} 5}$ Marina Vance, ${ }^{6}$ Jason C White, ${ }^{7}$ Mark R Wiesner ${ }^{\mathrm{ab}} *$

${ }^{a}$ Department of Civil and Environmental Engineering, Duke University, 121 Hudson Hall, Durham, NC USA

${ }^{\mathrm{b}}$ Center for the Environmental Implications of NanoTechnology (CEINT), USA

${ }^{\mathrm{c}}$ Department of Soil and Environment, SLU, Box 7014, 75007 Uppsala, Sweden

${ }^{\mathrm{d}}$ Eawag, Swiss Federal Institute of Aquatic Science and Technology, Überlandstrasse 133, CH-8600 Dübendorf, Switzerland

${ }^{\mathrm{e}}$ School of Geography, Earth and Environmental Sciences, University of Birmingham, Edgbaston, Birmingham, UK

${ }^{\mathrm{f}}$ Center for Environmental Nanoscience and Risk, University of South Carolina, Columbia, SC, USA

${ }^{g}$ Department of Civil and Environmental Engineering, Carnegie Mellon University, Pittsburgh, PA 15213, USA

${ }^{\mathrm{h}}$ Department of Earth and Environmental Sciences, School of Geography, University of Birmingham, Birmingham, UK

${ }^{i}$ EMPA, Swiss Federal Laboratories for Materials Science and Technology, Technology and Society Laboratory, Lerchenfeldstrasse 5, CH-9014, St. Gallen, Switzerland

${ }^{\mathrm{j}}$ Biochemical Sciences Division, National Institute of Standards and Technology, Gaithersburg, Maryland, USA

${ }^{\mathrm{k}}$ Department of Biology, Duke University, Durham, NC, USA

${ }^{1}$ The Chemours Company, Wilmington, DE, USA

${ }^{\mathrm{m}}$ Institute of Biomaterials and Biomedical Engineering, Rosebrugh Building, Room 407, 164 College Street, Toronto, Ontario M5S 3G9, Canada; Terrence Donnelly Centre for Cellular and Biomolecular Research, University of Toronto, 160 College Street, Room 230, Toronto, Ontario M5S 3E1, Canada; Department of Chemical Engineering, 200 College Street, Toronto, Ontario M5S 3E5, Canada; Department of Chemistry, 80 St George Street, Toronto, Ontario M5S 3H6, Canada; Department of Material Science and Engineering, 160 College Street, Room 450, University of Toronto, Toronto M5S 3E1, Canada

${ }^{\mathrm{n}}$ CNRS, Aix-Marseille Univ, IRD, INRA, Coll France, CEREGE, Europole Arbois, BP 80, 13545 Aix en Provence, France; Labex SERENADE, Europole Arbois, BP 80, 13545 Aix en Provence, France ${ }^{\circ}$ NEED (Jaydee Hanson)

${ }^{\mathrm{p}}$ School of Chemical, Biological, and Environmental Engineering, Oregon State University, USA

${ }^{\mathrm{q}}$ Department of Civil and Environmental Engineering, Howard University, Washington, USA

${ }^{\mathrm{r}}$ Department of Environmental Geosciences and Environmental Science Research Network, University of Vienna, Althanstr. 14, 1090 Vienna, Austria

${ }^{\mathrm{s}}$ Environmental Laboratory, U.S. Army Engineer Research and Development Center, Vicksburg, USA 39180

${ }^{\mathrm{t}}$ Arizona State University, School of Sustainable Engineering and The Built Environment, Box 3005,

Tempe, AZ 85287-3005, United States 


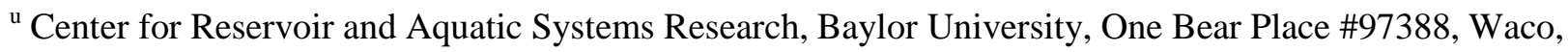
TX 76798, United States; Department of Environmental Science, Baylor University, One Bear Place \#97266, Waco, TX 76798, United States; Institute of Biomedical Studies, Baylor University, One Bear Place \#97266, Waco, TX 76798, United States

${ }^{v}$ NEED (Chris Metcalf)

${ }^{\mathrm{w}}$ Departments of Soil Science, Chemistry, and Civil \& Environmental Engineering, University of WisconsinMadison, 1525 Observatory Drive, Madison, WI, USA

${ }^{\mathrm{x}}$ Institute of Environmental Sciences (CML), Leiden University, Leiden, The Netherlands; National Institute of Public Health and the Environment, Center for Safety of Substances and Products, Bilthoven, The Netherlands

${ }^{y}$ National Institute of Public Health and the Environment (RIVM), Centre for Sustainability, Environment and Health, P.O. Box 1, Bilthoven, The Netherlands

${ }^{\mathrm{z}}$ Centre for Environmental and Marine Studies (CESAM), Department of Chemistry, University of Aveiro, 3810-193 Aveiro, Portugal

${ }^{\dagger}$ Aix Marseille Univ, CNRS, IRD, INRA, Coll France, CEREGE, Aix-en-Provence, France

${ }^{*}$ nanoRisk Analytics, LLC, Auburn, CA, USA

$\S$ Centre for Ecology and Hydrology, Wallingford, Oxfordshire OX10 8BB, UK

"I Department of Environmental and Molecular Toxicology, Environmental Health Sciences Center, Marine and Freshwater Biomedical Sciences Center, Oregon State University, Corvallis, OR 97331-7301, United States

${ }^{1}$ Department of Chemical Engineering, McGill University, Montreal, QC, Canada

${ }^{2}$ Ministry of Infrastructure and the Environment, Rijnstraat 8, 2515 XP, The Hague, The Netherlands; Project Office ProSafe PB 73, Postbus 1, 3720 Bilthoven, BA, Netherlands

${ }^{3}$ CGI, Montreal, Canada

${ }^{4}$ Department of Chemistry, Duke University, Durham, USA

${ }^{5}$ Department of Plant and Soil Sciences, University of Kentucky, Lexington, KY, USA

${ }^{6}$ Institute for Critical Technology and Applied Science, 410 Kelly Hall, Virginia Tech, Blacksburg, VA 24061-0420, USA

${ }^{7}$ Department of Analytical Chemistry, The Connecticut Agricultural Experiment Station, New Haven, Connecticut 06504, USA 


\begin{abstract}
The chemical composition and properties of environmental media play defining roles in determining nanomaterial (NM) transport, fate, biouptake, and even organism response. To compare and interpret experimental data, it is essential that sufficient context be provided for describing the physical and chemical charactheristics of the setting in which a nanomaterial may be present. While the nanomaterial environment, health and safety (NanoEHS) field has agreed upon some foundational aspects of harmonization to allow data comparison and re-use (e.g. the need for standardized materials, that a minimum set of material characterizations are required, and the need for consensus on specific assays for measuring these key parameters), the missing piece is for these standard tests on standard materials to be carried out within a commonly adopted set of consistent media. Since most of the NM properties driving environmental beaviour and toxicity are context-dependent, this missing piece of media harmonization is absolutely critical. Based on a workshop in March 2016 at Duke University, a set of characteristics are recommended for consistent reporting across five categories of test media: Aquatic Testing Media, Soil and Sediment Testing Media, Biological Testing Media, Engineered Systems Testing Media and Product Matrix Testing Media. Where available and sensible, we have in some cases recommended specific standardized media including set values for these consistently reported characteristics. Definitions and detail level of the recommendations vary across these media categories, reflective of the variation in the maturity of their existing definitions and associated measurement techniques, variation in utility and relevance of standardizing values in addition to simply standardizing reporting requirements, and in the availability of established standard reference media. Our expectation is that community utilization of these media harmonization recommendations will facilitate the generation of integrated comparable datasets. This will in turn allow testing of the predictive utility of functional assay measurements on nanomaterials in relevant media, support investigation of first principles approaches to understand behavioral mechanisms, and support categorization strategies to guide research, commercial development, and policy.
\end{abstract}

\title{
Environmental impact statement
}

To support regulatory and other environmental evaluation of nanomaterials, efficient generation of large arrays of standardized and comparable data are vital. To fulfill these requirements, it is essential that the selected set of parameters allows investigation of possible effects of both the surrounding medium and the nanomaterial properties on various endpoints. The authors propose minimum sets of parameters needed to provide such context in five system categories and provide the rationale for their designation. Adherence to adequate media characterization provides a basis for comparison while allowing researchers to employ any medium of choice with regard to parameter values. In some cases, standard media are also proposed, calling for specific parameter values that allow studies to be directly compared and benchmarked.

\section{List of abbreviations}

ALI - air-liquid interfaces; ASTM - American Section of the International Association for Testing Materials; ASW - Artificial Seawater; AVS - acid volatile sulfide; BOD - Biological Oxygen Demand; CNTs - carbon nanotubes; COD - Chemical Oxygen Demand; DIW deionized water; DMEM - Dulbecco's Modified Eagle's medium; DOC - dissolved organic 
carbon; EHS - Environmental Health and Safety; ENTM - Environmental Nano Testing Media; EU - European Union; FAs - Functional assays; FBS - foetal bovine serum; ISA-TAB-nano Investigation-Study-Assay data capture approach using delimited tabs; MBL - Marine Biological Laboratory; MHW - Moderately Hard Water; MHRW - Moderately Hard Reconstituted Water; MSW - Municipal solid waste; NCI NanoWG - National Cancer Institute Nanotechnology Working Group; NM - nanomaterial; NOM - natural organic matter; NZVI - nano zero-valent iron; OECD - Organization for Economic Cooperation and Development; SF - serum-free; SRMs - standard reference materials; SVI - volume index; TOC - total organic carbon; TSS Total Suspended Solids; US EPA - United States Environmental Protection Agency; VSW Very Soft Water; WWTP - wastewater treatment plant.

\section{INTRODUCTION}

The chemical composition and properties of environmental media play defining roles in determining nanomaterial (NM) transport, fate, biouptake, and even organism response. To compare and interpret experimental data, it is therefore essential that sufficient context be provided for describing the chemical dimensions of the setting in which a nanomaterial may be present. The Nanomaterial Environment, Health and Safety (nanoEHS) field has agreed upon the need for standardized NMs, ${ }^{1}$ that a minimum set of NMs characterization is required (although

the specifics are still debated), ${ }^{1}$ and even agreed upon specific assays for key parameters. ${ }^{2-4}$ The missing piece is for the nanomaterial testing community to carry out these standard tests on standard NMs within a commonly adopted set of consistent media, since most of the NM properties driving environmental behavior and toxicity are context-dependent. This will serve to build in a measure of quality assurance to the resulting data, and the premeditated interoperability ${ }^{5}$ will make resulting datasets more conducive to modeling and cross-study analyses. Here we use NM to refer to nanomaterials generally, since the advancement of nanoEHS has brought increasing understanding of the relevance of nanoscale materials of engineered, incidental, and natural origin, and the testing of all categories of NMs benefits from efforts to harmonize datasets.

It has been proposed that aggregated semi-empirical parameters called functional assays (FAs) be investigated for their utility in predicting nanomaterial behavior in complex systems. ${ }^{6}$ Functional assays to test dissolution rate, ${ }^{7}$ attachment efficiencies, ${ }^{8}$ and reactivities of NM would help to categorize these materials at various stages of their lifecycles in a way that is meaningfully predictive of their potential subsequent transport and impact. Besides capturing the functional behaviors must useful for forecasting impacts, the parameters generated by FAs would be inherently inclusive of the combination of intrinsic nanomaterial characteristics, extrinsic nanomaterial characteristics, and the environmental media characteristics that determined the state of those extrinsic properties.

Consistent testing of FA parameters describing nanomaterials in harmonized media will allow for the generation, integration and analysis of comparable data to enable screening-level forecasts of NM behavior and impacts, as well as to ultimately enable investigations into mechanisms based on first principles. As a first step then, the nanomaterial testing community must adopt a suite of relevant media in which to conduct functional assays. Establishing a set of 
consistently defined media will not only serve to build in a measure of quality assurance to the resulting data but will make resulting datasets more conducive to modeling and cross-study analyses.

To address this need for media harmonization, an expert workshop was convened in February 29 through March 2 of 2016 entitled "Environmental Nano Testing Media (ENTM) Harmonization". This manuscript presents the resulting recommendations as a first step in proposing relevant and consistently characterized media types in which nanomaterial characterization and testing should be carried out, along with proposed media characterization parameters that should be consistently captured and reported. The intent is to propose useful steps toward harmonization, acknowledging that this represents a snapshot in time of where the field is now, but converging on a handful of high priority media and matrices that we collectively endorse. Where appropriate, we also propose the adoption of some defined values for those parameters in common systems to support maximum comparability in emerging datasets. It should be clearly stated that these media, though proposed for NM testing, are defined here without any NMs in them.

The authors therefore propose minimum sets of parameters needed to provide such context in the various system categories and provide the rationale for the designation of these parameters. A definition of what constitutes adequate media characterization differs from specification of media standards or characterization in that media. Characterization allows researchers to employ any medium of choice, whereas media standards allow studies to be directly compared and benchmarked.

It may also be desirable to focus experimental efforts, where possible, on a limited number of well-defined media to further enhance the ability to compare results between laboratories and experimental approaches. With this goal in mind, we also designate a limited number of reference media for use in experiments where these ranges of parameter values would be appropriate.

On community-generated harmonization guidance. These recommendations represent a usercommunity consensus on approaches for harmonization on behalf of a collaborative sub-set of the nanoEHS field, as distinct from products of official standards organizations and processes (e.g. ASTM or OECD). The authors hope that this framework and the recommended media will better support downstream data integration, and provide helpful community-based input to discussions in the US and EU regarding more formal standardization processes for generating and storing integrated data. In the broader arena of nanomaterial testing and data integration, there have been some early successes with the model of community-initiated or communityfacilitated harmonization processes that can serve a complementary role to formal standardization processes in terms of supporting cross-disciplinary translation and education on appropriate method applications and standards adoption. Two examples include the development of the ISA-TAB-nano data sharing file format extension by the open National Cancer Institute Nanotechnology Working Group (NCI NanoWG) ${ }^{9}$ and the community-developed guidance on the proper execution and interpretation of zeta potential measurements. ${ }^{10}$ Similar to those examples, here we have developed proposed media for environmental and biological nanosafety assessment research and their parameters from within a group of researchers across academic, 
commercial and governmental sectors who are already immersed in investigating, modeling, and making decisions based on forecasts of nanomaterial behavior and effects.

A harmonized approach to gathering data to allow cross-study comparison through integration into a knowledge commons (database) that can be mined by multiple contributing researchers is practically necessary. Beyond this, such harmonization is an acknowledgment of a philosophical and cultural shift required to address interlinked problems with the size and complexity of forecasting the behaviors and impacts of dynamic NMs. Community adoption of communitydefined minimum reporting requirements for relevant media in which to test nanomaterials can foster the culture of shared, integrated research strategies as well as provide guidance and feedback to official standardization processes about current research consensus that can feed into standard test guidelines, as well as highlighting research needs and emerging datasets that will facilitate building of weight of evidence arguments through enhanced inter-comparability.

\section{WORKSHOP METHODS}

While consistency across NM testing media is important for integration, harmonized media will only be adopted if they also represent relevant systems with characteristics that support the investigation of individual researchers' existing questions, and have been considered in the context of the unique challenges presented by nanomaterials, with their large reactive surface areas. This is the reason for pursuing a community-driven approach to consider and recommend media for broad adoption in nanosafety fate, behavious and effects research and testing, and for engaging experts across an array of nanoEHS disciplines representing research, government and commercial sectors, and including North American, European, and Asian perspectives.

A working group of forty-one experts representing different disciplines, geographies and sectors was convened at Duke University. Attendees were asked to provide input prior to the workshop regarding classes of media that were important to address, any specific defined media they recommended for consideration, and critical parameters necessary to describe these media types. Breakout groups were organized to address 5 categories of communally-defined priority systems, and workshop activities were designed to move each breakout group through the process of: A) reaching consensus on media types within the category, B) arrive at consistent parameters that must be measured for each media type, and C) draw upon existing standard systems wherever appropriate to define values for the consistently defined parameters. Workshop process and outputs are depicted in Figure 1 generally; more detail on the workshop method is available in the Supplementary Information section of this manuscript. 


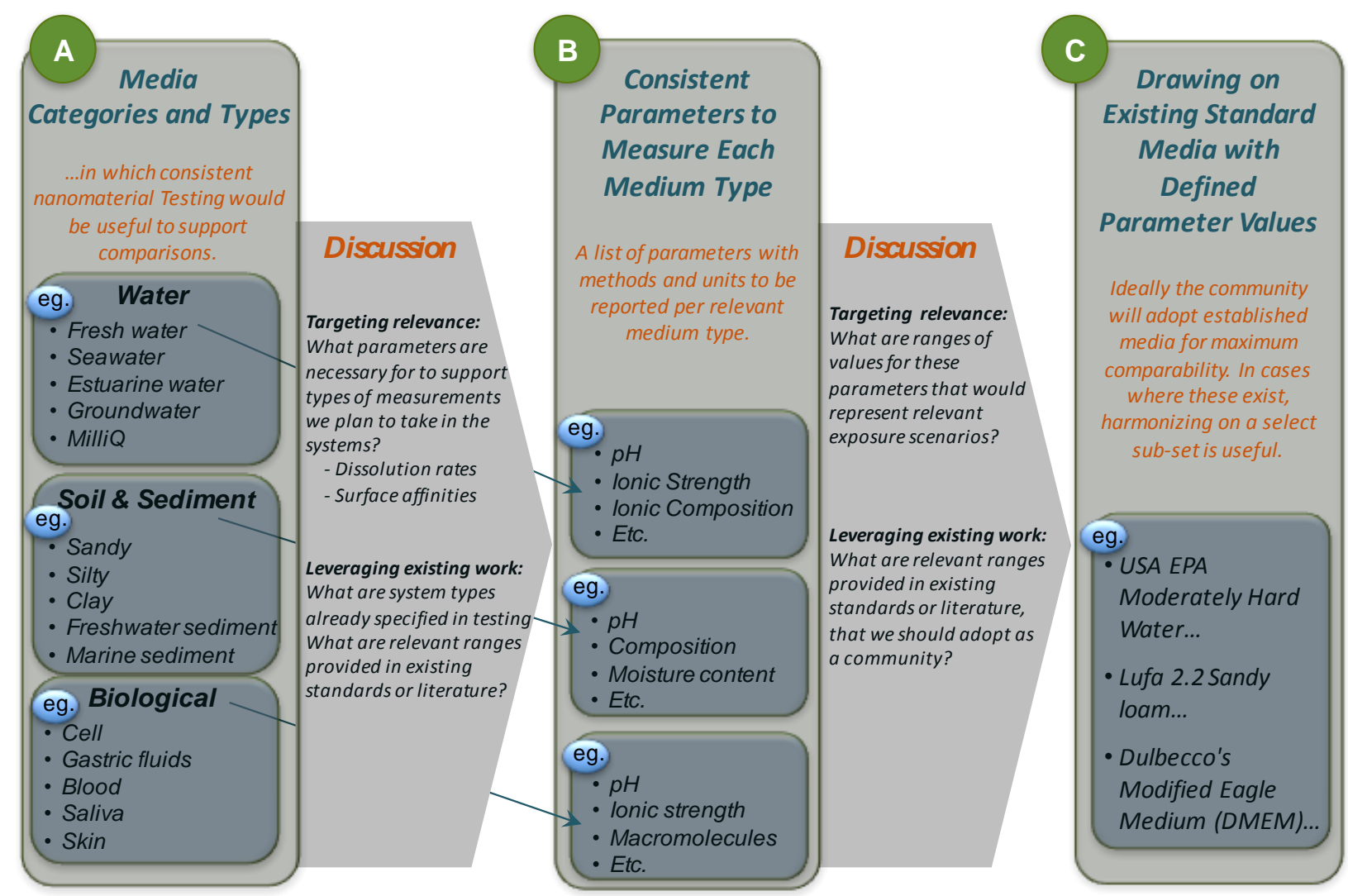

Figure 1: Workshop method overview; corresponds to resulting recommendations

\section{HARMONIZED MEDIA RECOMMENDATIONS}

Recommendations are presented here for harmonizing across five broad categories of testing media, all identified as important for relevant testing of nanomaterial behavior in terms of investigating both exposure and hazard endpoints. The definitions and detail level of recommendations vary across these media categories, reflective of the variation in the maturity of their existing definitions and associated measurement techniques and in the availability of established standard reference media. The media considered are aqueous and solid phase in nature; atmospheric media are not considered in this paper.

The broad categories presented here include:

- Aquatic Testing Media

- Soil and Sediment Testing Media

- Biological Testing Media

- Engineered Systems Testing Media

- Product Matrix Testing Media

Different media categories presented different challenges, ranging from some (e.g. soils) with an enormous number of competing standards from which to select the most critical representative systems and parameters, to some (e.g. product testing media) which are conceptually necessary to provide the basis for important measurements across material life-cycles, but which have not 
been previously defined and require iterative improvements to associated analytical techniques. The content and detail level of the harmonization recommendations vary accordingly across these categories, but are linked by the shared mission of advancing the state of harmonization in future investigations.

\subsection{Aqueous media}

\subsubsection{Context and background}

Aquatic systems are of particular relevance to nanomaterial testing, because engineered nanomaterials have been predicted to arrive in natural waters via multiple routes of release via wastewater treatment plant effluent, run-off from agricultural and urban areas, and deposition by rain. $^{11,12}$

Aquatic systems can be broadly differentiated based on levels of salinity, ranging from marine to soft freshwater ecosystems. Low salinity freshwater includes lakes, rivers and streams, urban runoff, ground water, rain water, ephemeral pools, and tap water; all of which have a wide range of possible water quality characteristics. Representative parameters are given in Table S1. The characteristics of estuarine systems are also highly variable, as well as dynamic, depending on tidal cycles, freshwater discharge and Coriolis effects. The characteristics of marine systems close to land are similarly dynamic. Open ocean ecosystems are less variable, yet are influenced by the degree of biological productivity, which in turn is governed by nutrient inputs, temperature, and other factors. Therefore, there is a wide range of test systems that could be developed to represent the range of scenarios where nanomaterials may be present in an aquatic system.

The authors acknowledge that other factors may well be strong determinants of NM behavior outcomes depending on the scenario, including light, temperature, and well-defined natural organic matter (NOM). For a streamlined first step toward harmonization, we focus discussion on the chemical composition of aquatic media rather than the entirety of parameters required to define aquatic systems that would additionally include conditions of energy flux (e.g., light, mixing, heat) and biotic composition.

Dissolution and agglomeration are perhaps the most important transformation processes affecting fate and toxicity of NMs within aquatic systems, although many others exist. ${ }^{13}$ Understanding the extent of NM dissolution and agglomeration in aquatic test systems is therefore essential for estimating environmental risks. The extent of these transformations in a test system will depend on physicochemical conditions, such as concentrations of dissolved organic carbon (DOC), $\mathrm{pH}$, ionic strength and redox conditions (i.e. oxidizing or reducing environment), in addition to NM specific properties and concentration. ${ }^{6,14,15}$

\subsubsection{Recommended media and parameters}

Table 1 summarizes the key variables that are important in defining the fate and toxicity of NMs within the three generic environmental aquatic ecosystems considered by this group: Freshwater, Estuarine, Marine. 
In addition to the three environmental categories of aqueous systems, deionized water (DIW), in which ions are removed through an ion exchange process, is one of the media options that many NM research laboratories have already converged on. DIW has been commonly used for testing and characterization of NMs because it alleviates any interference from ions on the NM. Although not representative of a natural water system, DIW is likely the medium that is most often and most easily implemented for comparison across laboratories. It is used for the synthesis of many NMs as well as the dilution of media. The $\mathrm{pH}$ of DIW is often slightly lower than 7 due to the influx of $\mathrm{CO}_{2}$; however, the low concentrations of ions in DIW may confound $\mathrm{pH}$ measurements that require a minimal level of ions for the electrode to function properly.

For each of the systems presented in Table 1, we propose tiers of key characteristics in terms of primary (absolutely required) and secondary (required in cases where these characteristics are available and/or pertinent to the specific measurement being taken). Additionally, the list of characteristics here are intended to apply to data collected and reported on either naturally sourced or laboratory-simulated waters within these categories.

Table 1: Minimum set of parameters recommended for inter-study comparison of the fate and effects of NMs in aqueous media

\begin{tabular}{|c|c|c|}
\hline Media type & Primary Measurements & Secondary Measurements \\
\hline Freshwater & $\begin{array}{l}\text { - } \mathrm{pH} \\
\text { - Ionic strength } \\
\text { - Major cations (e.g. hardness) } \\
\text { - Major anions (e.g. alkalinity) } \\
\text { - Dissolved organic matter (e.g. DOC) }\end{array}$ & $\begin{array}{l}\text { - Specific anionic ligands (e.g. sulfate, } \\
\text { chloride) } \\
\text { - Key nutrients (e.g. nitrogen \& } \\
\text { phosphorus species) } \\
\text { - Redox potential } \\
\text { - Particulate matter: } \\
\text { ○ Organic } \\
\text { ○ Inorganic }\end{array}$ \\
\hline Estuarine & $\begin{array}{l}\text { - Ionic strength } \\
\text { - Dissolved organic matter (e.g. DOC) } \\
\text { - } \mathrm{pH}\end{array}$ & $\begin{array}{l}\text { - } \quad \text { Major anions (e.g. alkalinity) } \\
\text { - } \text { Key nutrients (e.g. nitrogen \& } \\
\text { phosphorus species) } \\
\text { - } \text { Dissolved organic matter (e.g. DOC) } \\
\text { - } \text { Particulate matter: } \\
\text { ○ Organic } \\
\text { O Inorganic }\end{array}$ \\
\hline Marine & $\begin{array}{l}\text { - Ionic strength } \\
\text { - Dissolved organic matter (e.g. DOC) } \\
\text { - } \mathrm{pH}\end{array}$ & $\begin{array}{l}\text { - } \text { Key nutrients (e.g. nitrogen \& } \\
\text { phosphorus species) } \\
\text { - Particulate matter: } \\
\circ \text { Organic } \\
\text { ○ Inorganic } \\
\end{array}$ \\
\hline DI & $\bullet \mathrm{pH}$ & \\
\hline
\end{tabular}

Discussion of primary parameters. The minimum specifications considered to be adequate for evaluation of NM data in all aquatic systems were quantification of $\mathrm{pH}$, ionic strength, and a measure of DOC. Additional characterization of the composition of ionic components, such as 
hardness and alkalinity, was also considered to be essential for freshwater systems. The relative uniformity of seawater composition and their low DOC concentrations suggest that characterization of DOC may be a secondary consideration in marine systems.

Discussion of secondary parameters. In addition to the parameters considered to be essential for minimum characterization of aqueous media, several additional parameters were identified as being highly desirable. In some cases, synthetic laboratory media include detailed analysis or complete specification of the medium content. In these cases, a reference for these media should be provided that will allow readers to obtain the full details of media composition. However, in many cases, such as where experiments are performed in field or mesocosm conditions, the complete composition of the medium will be unknown. In these cases, measurement of specific divalent ions $\left(\mathrm{Ca}^{2+}\right.$ and $\left.\mathrm{Mg}^{2+}\right)$ are among the most important secondary measures for characterizing ionic content beyond total hardness and conductivity. Measurement of nitrogen and phosphorus species are highly desirable from the perspective of their potential impact on biotic components in a given experiment. These species, while likely to be present in low concentrations, are also potentially important in determining surface properties of NMs due to their propensity for inner sphere coordination with NM surfaces resulting in effects on NM surface charge. In the case of nanoscale silver (nanoAg), it will also be important to consider the concentration of $\mathrm{Cl}^{-}$anions. Alkalinity was also deemed to be an important parameter as a partial characterization of the anionic composition of aqueous solutions.

Most aquatic solutions include complex mixtures of dissolved organic matter and naturally occurring particulates that may merit additional characterization that, in the simplest instance, include measurements of Total Organic Carbon (TOC) in unfiltered samples and in samples that have been membrane filtered (typically, $0.2 \mu \mathrm{m}$ or $0.45 \mu \mathrm{m}$ membranes). The selection of size may be influenced by what specific information is sought about the system; if it is desirable to capture agglomerates of nanoscale particles, $0.45 \mu \mathrm{m}$ may be preferable. The materials retained by such membranes are commonly used to characterize the mass concentration of total suspended solids, which may give a very approximate estimate of the potential for NM heteroaggregation. Measures of organic carbon in the unfiltered (TOC) and filtered (DOC) samples additionally yield estimates of the percent organic carbon averaged over all suspended particulates, which may play a role in determining NM stability and affinity of these background particulates for heteroaggregation with engineered NMs.

Measurement of the UV absorbance at $254 \mathrm{~nm}$ in filtered samples provides additional information regarding the quality of the organic matter in terms of aromaticity, often normalized by the DOC concentration and reported as the specific UV absorbance. ${ }^{16}$ More detailed analysis of suspended particulates in terms of particle size distributions and the electrophoretic mobility of suspended particulates are also among the secondary parameters that may be important in specific experimental settings. Though measurements of naturally occurring background particulate size distributions and concentrations would be considered required input for modeling NM heteroagglomeration, persistence and transport, it is recognizecd that many tests seek to evaluate NM toxicty or dissolution in the absence of heteroagglomeration. Therefore, characterization of the naturally occurring background particulate phases present in these systems was consodered to be a secondary consideration in these instances.

Table 2. Units, rationale and references for recommended parameters to characterize aqueous media 


\begin{tabular}{|l|l|l|l|l|}
\hline \multicolumn{1}{|c|}{ Parameters } & \multicolumn{1}{c|}{ Units } & \multicolumn{1}{|c|}{ Rationale } & Method Type & Reference \\
\hline $\mathrm{pH}$ & $-\log \mathrm{M}$ & $\begin{array}{l}\text { Assay independent indication of water } \mathrm{pH} \text {, good for } \\
\text { comparability }\end{array}$ & Standard & 17,18 \\
\hline Ionic strength & $\mathrm{mmol} / \mathrm{L}$ & $\begin{array}{l}\text { Calculate from either reagent addition or from conductivity } \\
\text { measurements }\end{array}$ & Standard & 19 \\
\hline Major cations & $\mathrm{mmol} / \mathrm{L}$ & Importance in NM stability and properties of organic matter & Assay-specific & 20 \\
\hline Major anions & $\mathrm{mmol} / \mathrm{L}$ & importance in NM stability and properties of organic matter & Assay-specific & 20 \\
\hline $\begin{array}{l}\text { Dissolved organic } \\
\text { carbon (DOC) }\end{array}$ & $\mathrm{mg} / \mathrm{L}$ & Importance in cation binding and NM stability & Standard & 21 \\
\hline $\begin{array}{l}\text { Specific anionic ligands } \\
\text { (e.g. sulfate, chloride) }\end{array}$ & $\mathrm{mmol} / \mathrm{L}$ & Importance in NM stability and properties of organic matter & Assay-specific & 20,22 \\
\hline $\begin{array}{l}\text { Redox potential } \\
\text { PV }\end{array}$ & Possible electron sources/ sinks & Assay-specific & 23 \\
\hline $\begin{array}{l}\text { Particulate matter: } \\
\text { Inorganic }\end{array}$ & $\mathrm{mg} / \mathrm{L}$ & Importance in heteroaggregation & Assay-specific & 24,25 \\
\hline
\end{tabular}

3.1.3. Considerations of benchmark media for specific parameter values

In laboratory tests where a choice of aquatic media may be available, three reconsituted waters are recommended as a basis for simulating the three broad categories of aquatic systems indicated above. For freshwater with low hardness, a medium conforming to the specifications for the U.S. Environmental Protection Agency (US EPA) Very Soft Water (VSW) is proposed. Where experimental conditions are meant to simulate fresh waters with a significant concentration of monovalent and divalent ions, a medium conforming to the specifications for the EPA Moderately Hard Water water (MHW) is proposed. Commercially available products are proposed for simulating seawater or, at various degrees of dilution, estuarine waters. The rationale for recommending each of these media formulations is given in the following sections.

Rationale for Very Soft Water (VSW) recommendation. As discussed above, the USEPA reconstituted freshwaters may be formulated to have a range of hardness values. For functional assays ${ }^{6}$ and toxicity bioassays, lower $\mathrm{Ca}^{2+}$ concentration/hardness may be advantagous for maintaining more stable dispersions in the case of charge-stabilized NMs, although the impacts on animal health in this diluted media must be considered. ${ }^{26-28}$ The lowest hardness standard water (10 to $13 \mathrm{mg} / \mathrm{L}$ as $\mathrm{CaCO}_{3}$ ), which has relevance to alpine streams and e.g. Canadian Shield lakes, is Very Soft Water (VSW). This test water has the lowest $\mathrm{Ca}^{2+}$ content $(0.044 \mathrm{mmol} / \mathrm{L})$ of any available test standardized test water. ${ }^{29}$ Relative to higher $\mathrm{Ca}^{2+}$ concentration/hardness media, VSW and comparable low hardness media have been shown to enable higher stability of carbon $\mathrm{NMs},{ }^{30,31}$ nano $\mathrm{Ag}^{27,} 32-34$ and other metal NMs ${ }^{35}$ during fate and toxicity testing, when charge stabilized. Other coatings using steric stabilizaton methods show less sensitivity to ion concentration and composition. ${ }^{36,37}$

Rationale for Moderately Hard Water $(M H W)$ recommendation. The USEPA has standardized a series of reconstituted freshwaters for toxicity (hazard) testing. Regulatory testing programs in the USA, under the umbrella of the Clean Water Act, that require use of these test waters include industrial effluent testing ${ }^{38}$ and open water dredged material placement operations. In addition, 
testing for superfund toxic substances and pesticides ${ }^{39}$ regulatory programs use USEPA test waters. These standard test waters range in hardness from 10 to $320 \mathrm{mg} / \mathrm{L}$ as $\mathrm{CaCO}_{3}$, (10 ${ }^{-2}$ to 3.2 $\mathrm{mmol} / \mathrm{L}$ of $\mathrm{Ca}^{2+}$ ) to allow selection based on site-specific relevance.

Moderately Hard Water (MHW), with an acceptable hardness range of 80 to $100 \mathrm{mg} / \mathrm{L}$ as $\mathrm{CaCO}_{3}$ (or 0.8 to $1 \mathrm{mmole} / \mathrm{L}$ ) is the most commonly applied test water for hazard assessment. MHW is a reconstituted water, designed generically to satisfy the basic requirements of taxonomically diverse freshwater organisms (algae, invertebrates, fish) that are used in standardized acute and chronic toxicity test methods ${ }^{40,41}(24)(25)$. The recipe for MHW is freely available and consists of four simple salts $\left(\mathrm{NaHCO}_{3}, \mathrm{CaSO}_{4}, \mathrm{MgSO}_{4}, \mathrm{KCl}\right)$ dissolved in ultrapure water; this relatively simple ionic composition (Table SI.1.3) may be considered more amenable to modeling relative to other media with a more complex ionic composition. There is a very large database of standardized toxicity tests using this test system for both traditional substances and NMs; ${ }^{26,} 42$ because of this coalescence around MHW use for toxicity tests, it makes sense to adopt similar media for exposure research as well.

Limitations are also recognised in the MHW recommendation. While MHW was the standardized test media that most closely represented the ideal parameters for NM hazard testing, it must be recognized that it is not ideal for NM dispersion and stability investigations. It is a USA-centric test water that may be used less frequently relative to OECD and ISO test media in laboratories outside of the USA and is not used in OECD testing standards (which are internationally recognized). Its $\mathrm{Ca}-\mathrm{Mg}$ ratio is not representative of surface waters under certain conditions, ${ }^{29}$ and its sulfate and chloride concentrations are too high and low, respectively, for idealized NM exposure testing scenarios. However, this is balanced by the reproduceability and ease of synthesis of the water with appropriate hardness, $\mathrm{pH}$, and ionic strength.

Rationale for Artificial Seawater (ASW) recommendation. The primary parameters of concern when attempting to model seawater are ionic composition, and to a lesser extent trace elements. As is the case for most of the media categories and types covered in this paper, multiple competing seawaters have been defined without consensus adoption to date. Many studies have been conducted with filtered natural seawater ${ }^{43}$ or a mixture of natural and artificial seawater ${ }^{44}$ (28), which can vary temporally and spatially, necessitating extensive characterization of each batch collected for site specific accuracy. However, compared to terrestrial waters, seawaters are relatively homogenous, and for the purposes of enabling cross-comparison of data we propose agreement on a harmonized recipe. There are numerous commercially available ASW alternatives, several of which have been used extensively in scientific research (e.g. Instant Ocean and Crystal Sea Marine Mix). ${ }^{45}$ The ionic and elemental compositions of these are quite similar to actual seawater, ${ }^{46}$ but quality control and batch variability are a significant concern. Alternatively, several artificial seawater standards are commonly used and can be made with reagent-grade chemicals. EPA synthetic seawater, ${ }^{41}$ ASTM D1141-98, ${ }^{47}$ and Marine Biological Laboratory $(\mathrm{MBL})^{48}$ are a few examples.

Given the need for quality control and reproducibility, there are significant concerns about recommending commercially available ASW mixtures, or filtered natural seawater. Based primarily on batch-to-batch variability of commercially available artificial seawaters, we recommend using EPA artificial seawater (EPA ASW), made with reagent-grade chemicals, at 
35\% salinity. Ionic composition and the trace element complexity of EPA ASW are similar to ASTM D1141-98 Substitute Ocean Water. We are recommending EPA ASW as the recipe is freely available. The inclusion of trace elements along with the major ionic components allows EPA ASW to be used for both acute and chronic experiments, ${ }^{40}$ whereas standard MBL does not contain trace elements (although several variants exist for MBL with increased complexity). ${ }^{49}$ EPA ASW is complex enough to be a reasonably environmentally relevant standard, without being too complex to complicate modeling efforts.

For estuarine subsystems, we recommend using 3.5\% salinity EPA ASW, although species' physiological requirements may prevent the usage of this salinity. Alternative dilutions of EPA ASW may be used where necessary to accommodate differing species' requirements. In all cases, full documentation is needed.

Rationale for not recommending other available standard bioassay test waters.

Some key limitations of the OECD and ISO standard waters limit their broad applicability as a recommended standard freshwater for functional assays of NMs. For the OECD test waters, they are typically specified for individual test organisms to maintain that health of that test organism. It is unclear if the water recommended for algae and Daphnia magna, for example, would also be applicable for fish studies. In addition, the common test waters specified in OECD test methods such as M4 and M7 testing contain EDTA and a diverse array of trace elements and vitamins, which could dramatically impact the results for some NMs which may dissolve to varying degrees in the test waters. These media have also rarely been used for environmental fate testing of NMs so there may be additional unanticipated complications for the use of these media for newly developed functional assays, especially given the complex formulations of these media. Many of these limitations also apply to the ISO test media, such as its limited use in studies on the environmental fate of NMs and that it was developed for toxicity testing. Most importantly, this water has a very high calcium concentration $(2 \mathrm{mmol} / \mathrm{L})$, so the use of this water is less reflective of the conditions typically found in freshwaters compared to other water media.

\section{Experiment-specific Medium Amendments}

Amendments to reference media are proposed for simulation of dissolved organic matter and naturally occuring particles. Naturally occuring organic matter and particles are important components of aquatic ecosystems with, for example, DOC playing an important role in modifying NM surface chemistry, complexing dissolving metals and mediating photocatlytic reactions. ${ }^{13}$ Each of the recommended aquatic media described above may be amended with DOC and/or organic particles depending on experimental requirements, although it is critical to carefully describe the DOC composition and concentration.

\section{NOM Amendments}

NOM is a ubiquitous and important component of aquatic environments that plays critical roles in the colloidal stability, aggregation, transport, and bioavailability of NMs, as well as NMcontaminant interactions. Thus, NOM is a key component to be included in test systems for aquatic environments. In general, surface waters vary widely in NOM concentrations, ranging from 0.1 to $20 \mathrm{mg} \mathrm{L}^{-1}$. 50 , 51 The US EPA moderately hard water matrix that we are recommending for aquatic test systems contains only salts of major cations and anions, and no organic matter or suspended particulates. Therefore, NOM may be added to the test medium to 
better simulate surface water, marine and estuarine ecosystems in which NOM concentrations are elevated.

However, the types, composition and concentrations of NOM differ substantially among aquatic systems. Furthermore, NOM from different sources may vary significantly in physicochemical characteristics, such as molecular weight, relative contents of aliphatic versus aromatic carbon, the contribution of carboxylate and phenolic functionalities, and the ionization thresholds (i.e. $\log \mathrm{K}_{1}$ ). The commercially available model NOM products that have been commonly used in aquatic toxicity and geochemistry studies include Suwannee River humic acids, fulvic acids and NOM, Sigma-Aldrich humic acids, and Leonardite humic acids. There are advantages and limitations associated with all of these commercial products. For instance, while the SigmaAldrich humic acids are relatively cheap and can be purchased in large quantities, the source and extaction method is not well documented, they are high in calcium salts and tend to promote precipitation of inorganic components of the test medium when added at high concentrations. ${ }^{52}$ Suwannee River products are purified to remove metals and other impurities, and these materials are also extensively characterized and relatively homogeneous among a given batch. However, Suwannee River standard products are relatively expensive and can only be purchased in limited quantities (i.e. $4 \mathrm{~g}$ per year per researcher).

After weighing the advantages and disadvantages, we recommend addition to test systems of "Suwannee River Aquatic NOM". This product is concentrated from surface water using reverse osmosis technologies, according to the supplier, the International Humic Substances Society. We further recommend additions that yield a final DOC concentration of $5 \mathrm{mg}-\mathrm{C} \mathrm{L}^{-1}$; representing an intermediate concentration within the range of DOC typically found in surface waters, and estuarine ecosystems. ${ }^{53}$ Seawater DOC concentrations should be much lower, at a recommended concentration of $0.05 \mathrm{mg} / \mathrm{L}$. We recommend that NOM not be added to test systems that simulate groundwater and rain water. However, this highly processed product may not be representative of NOM in all natural environments; especially those in which biological productivity is high and contributes to elevated concentrations of complex biological molecules (e.g. polysaccharides, glycoproteins) in solution. Several commercial products are available that are used as sources of complex biological molecules in the food and cosmetic industries, and in other industrial applications, including alginate, xanthum gum, succinoglycan and gum Arabic. Again, balancing the disadvantages and advantages of these products, we recommend using alginate as an additive for test systems in which the addition of NOM is meant to simulate a highly productive biological system. Alginate is a highly water soluble mixture that is prepared as a sodium salt of alginic acid, which is an anionic polysaccharide isolated from brown algae. It is widely available in large quantities from many commercial suppliers. Because of the potential for variations between suppliers and from batch to batch, we recommend that the alginate be purchased in bulk and characterized fully before being used in aquatic test systems, with complete reporting of the characterisation alongside the experimetnal test outcomes.

Colloidal Ammendments. The colloids naturally present in aquatic systems consist of an inorganic fraction in addition to the previously discussed NOM. ${ }^{54}$ It has also been shown that these background particles can significantly impact the fate of NMs in the aquatic environment, such as by increasing sedimentation. ${ }^{55}$ For this reason, it is important to consider this component ubiquitously present in many aquatic systems. As this is a relatively complex agent, it is only of 
concern when heteroagglomeration and natural relevance is important for studies testing fresh and estuarine waters.

The inorganic colloids naturally present in oxic fresh water with the highest mass abundance are clays, silica and iron oxyhydroxyde particles. ${ }^{54}$ Although there are many different clay types such as Laponite, Kaolin and Montmorillonite, it is recommended to use a well characterized synthetic clay. This is due to these being (i) being widely available (ii) relatively constant quality and (iii) already well characterized. There are no clear standards available for inorganic background particulates. However, Laponite is the recommended clay as it fits the abovementioned criteria. Extensive descriptions of the characterization of Laponite may be found elsewhere. $^{56}$ Silica particles have been used for several applications ${ }^{8,57,58}$ and many are available for purchase, either synthetic or derived from a natural silica source. It is recommended to use particles smaller than $5 \mu \mathrm{m}$ and to use solid particulates in order to exclude the extra surface area and reactivity provided by porous particulates.

Background particulates specifically play a role in river and estuarine waters. As clays are the background particulates most often transported to the estuarine systems, the addition of quartz (silica) can be neglected for this system. ${ }^{54}$ For river systems both clay and silica particulates are thought to be representative of riverine background particulates. Iron oxyhydroxyde particulates were not considered, although they have been shown to have high surface areas in some systems when nano-scale particles are present. ${ }^{59,60}$

As a final thought, these artificial inorganic background particulates in any one of the aquatic media are not fully representative of a real natural system. A natural system would also include particulate matter related to algae and microorganisms; these are found to be of such relative complexity that suggesting specific measurement requirements would not be helpful to enhancing comparability when they would be added to one of the recommended aquatic media. However, the recommended media and background particulates could be taken as a starting point in studies aimed at investigating interactions of NMs with algae or microorganisms.

\subsubsection{Key challenges and trade-offs guiding parameter and benchmark suggestions}

To arrive at recommendations, compromises were made to define systems that would enable measurements while staying as close as possible to realistic, environmentally representative media.

\subsection{Soils, sediments and other important solid phases}

\subsubsection{Context and background}

NMs will become associated with a variety of solids (e.g. soil, subaquatic sediment, heat-treated sludges, plant residues) in built and natural environments. Note that only heat-treated biosolids will be considered in this section, whereas other wastewater treatment products are discussed in section 3.4 (Engineered waste systems). Deposition, when defined as the attachment and detachment processes of NMs and stationary surfaces, is an important interaction of NMs in 
solid phases, because it determines the extent of NM transport and most likely also their bioavailability $^{61}$ and toxicity. ${ }^{62}$

Functional assays (FAs) are, as discussed in the introduction, practical small-scale tests in a medium with sufficient complexity in composition to adequately capture the various processes that NMs may undergo in that specific system, e.g. a soil, sediment, or heat-treated sludge. The outcome of a functional assay is intended to provide rate (or if appropriate, equilibrium) data for a specific process affecting NM fate or bioavailability. The most critical parameters affecting the solids considered in this section are 1) attachment rate (affects mobility and bioavailability), 2) dissolution rate (affects persistence, bioavailability, and toxicity, 3) core material transformation rate (affects fate, bioavailability, uptake, toxicity), 4) bioaccumulation rate (affects toxicity, trophic transfer), and 5) toxicity (various lethal and sub-lethal endpoints will ultimately be considered). For example, the attachment rate of a NM in a soil can be used to model the transport of that NM through the soil if the relevant soil parameters (e.g. porosity and degree of saturation) are also known, or to describe heteroagglomeration rates with suspended solids in the water column. Assessment of the dissolution rate of a NM in a solid matrix can give some indication of its persistence in a selected system, or its ability to deliver potentially toxic ions to aquatic or terrestrial organisms. The dissolution rates of NMs in solid matrices will also inform persistence and provide knowledge regarding the form of the NM that is expected to be persistent in a given system if dissolution is not complete. The numerous acute and chronic toxicity assays utilized for risk assessment provide an indication of the potential for the NM to cause hazard. In all of these cases, the parameters provided in Table 3 can greatly affect the outcomes of the assay. The use of standard solids (e.g. soils or sludges) that hold these parameters roughly constant will be the simplest mechanism to readily compare across studies and across NM types. Tests in solids collected at a selected site should be characterized. This characterization is needed to explain differences in site-specific soils as compared with standard soils. Ultimately, relationships between e.g. standard soils and site-specific soils can be determined and used to predict the fate of a new NM in a site-specific soil based on its behavior in the standard soil.

\subsubsection{Recommended media and parameters}

Considering the current state of knowledge about sinks for NMs, exposure routes, and sensitive ecosystems, the following prioritization of solid phases requiring standardization was created (Table 3). The highest priority is given to agricultural soils that were identified as the most probable sink for many NMs, via application of heat-treated sludges and nano-agrochemicals $(37,38)$. NMs can arrive into freshwaters via wastewater treatment plant (WWTP) effluents and run-off from agriculture and urban areas, leading to some build-up in sediments after heteroaggregation and sedimentation, ${ }^{55}$ but many NMs are likely to accumulate in estuarine sediments because of the sharp ionic strength gradient in estuarine zones leading the NMs to agglomerate and sediment here. ${ }^{15,}{ }^{63}$ Limited movement to unconsolidated aquifers beneath agriculture fields is assumed given the limited vertical migration of NMs through porous media ${ }^{61}$, but direct application of e.g. nano zero-valent iron (NZVI) and NM seepage from landfills may be a significant source in selected areas. Less researched sinks include plant residues that potentially receive NMs, e.g. from applied agrochemical NMs such as nanopesticides and nanofertilizers. ${ }^{64,}{ }^{65} \mathrm{NMs}$ that leach off plants after spraying may also mediate NM fluxes towards other compartments such as soils. Other solid systems such as composts, urban soils, 
unmanaged soils, marine sediments and animal manures were prioritized less (Table 3), because influx is expected to be low, e.g. unmanaged soils are only subject to atmospheric deposition, or because very limited information is available on potential influx as is the case with animal manures.

Table 3: Minimum set of parameters recommended for inter-study comparison of the fate and effects of nanomaterials in soil and sediment media

\begin{tabular}{|c|c|c|}
\hline Media type & Primary Measurements & Secondary Measurements \\
\hline $\begin{array}{l}\text { Agriculture and } \\
\text { forestry soils }\end{array}$ & $\begin{array}{l}\text { - Soil pH } \\
\text { - TOC } \\
\text { - Texture } \\
\text { - Extractable } \mathrm{Si}, \mathrm{Ca}, \mathrm{Mg}, \mathrm{Fe}, \mathrm{Al}, \mathrm{Mn} \\
\text { - Redox potential } \\
\text { - Specific conductance }\end{array}$ & $\begin{array}{l}\text { - } \text { DOC } \\
\text { - Porewater } \mathrm{pH}\end{array}$ \\
\hline Heat-treated sludges & $\begin{array}{l}\text { - All agriculture soil parameters except } \\
\text { texture } \\
\text { - Total C, S, P, K, N and potentially toxic } \\
\text { metals } \\
\text { - Acid volatile sulfide (AVS) } \\
\end{array}$ & - All of the above \\
\hline $\begin{array}{l}\text { Subaquatic } \\
\text { sediments }\end{array}$ & $\begin{array}{l}\text { - All agriculture soil parameters } \\
\text { - AVS }\end{array}$ & - All of the above \\
\hline $\begin{array}{l}\text { Unconsolidated } \\
\text { aquifers }\end{array}$ & $\begin{array}{l}\text { - All agriculture soil parameters } \\
\text { - Effective porosity } \\
\text { - Grain size } \\
\text { - Dispersivity }\end{array}$ & - All of the above \\
\hline $\begin{array}{c}\text { Consolidated } \\
\text { aquifers }\end{array}$ & $\begin{array}{l}\text { - All agriculture soil parameters } \\
\text { - Equivalent aperture of fractures } \\
\text { - Coefficient of variation of fractures }\end{array}$ & - All of the above \\
\hline
\end{tabular}

Chemical, physical, and biological parameters relevant to the assessment of NM transport, exposure or hazard should be reported in soil studies. These parameters can be divided into those that are necessary for media standardization and interpretation of results across studies and those that are necessary to characterize only for specific functional assays. For example, determining the affinity of NMs for soil surfaces using a column study requires additional structural characterization compared to a batch mixing approach. Collecting and reporting the minimum selected parameters enables inter-study comparability of media and results, or can be necessary for conducting functional assays of critical NM-specific phenomena, such as dissolution, mobility (e.g., surface affinity, aggregation, detachment), transformation, bioaccumulation, and toxicity. Where available, standard methods should be used to measure these parameters, but it is recognized that measurement of some parameters will be assay-specific. In these cases, careful reporting of meta-data associated with the measurements will be necessary for comparability with other studies.

Solids (e.g. soils) are complex so there are many parameters that can affect the fate or toxicity of NMs in terrestrial systems (Table 3). Resource limitations will often lead to a smaller set of parameters that is effectively determined, compared to the ideal list for detailed mechanistic 
studies. Lists of minimum parameters for characterizing soil media were therefore compiled for consistently generating and interpreting data on transport, fate, and biological testing of NMs in soils (Table 4).

Table 4. Units, rationale and references for recommended parameters to characterize solid media

\begin{tabular}{|c|c|c|c|c|}
\hline Parameters & Units & Rationale & Method Type & Reference \\
\hline $\begin{array}{l}\mathrm{pH} \text { in } 1 \mathrm{M} \mathrm{KCl} \text { or } 0.01 \mathrm{M} \\
\mathrm{CaCl}_{2} \text { extract }\end{array}$ & & $\begin{array}{l}\text { Assay independent indication of pore } \\
\text { water } \mathrm{pH} \text { good for comparability }\end{array}$ & standard & 66 \\
\hline TOC & $\mathrm{mg} \mathrm{kg}^{-1}$ & $\begin{array}{l}\text { Immobile OM to which NM can attach, } \\
\text { contributes to structure, indicator of } \\
\text { biological activity }\end{array}$ & standard & 67,68 \\
\hline texture (clay, silt, sand) & $\%$ & $\begin{array}{l}\text { Indicator of } \% \text { mineralogical clays and or } \\
\text { oxides and thus of quantity of favorable } \\
\text { deposition sites for NMs, contributes to } \\
\text { structure, indicator of straining potential } \\
\text { and permeability, nutrient retention } \\
\text { capacity, Water Holding Capactiy, } \\
\text { dispersable clays }\end{array}$ & standard & 69 \\
\hline redox potential & $\mathrm{V}$ & $\begin{array}{l}\text { master variable for speciation, indicator of } \\
\text { microbial activity, controls extent of } \\
\text { dissolution of redox-sensitive NPs (Ag, } \\
\mathrm{Fe}, \mathrm{Al}, \ldots \text { ), especially in sludges }\end{array}$ & assay-specific & 70 \\
\hline $\begin{array}{l}\text { water extractable } \mathrm{Ca}, \mathrm{Al}, \mathrm{P} \\
\mathrm{Mn}, \mathrm{Fe}, \mathrm{Si}, \mathrm{SO}_{4}, \mathrm{Mg}, \mathrm{K}, \mathrm{Na} \\
\mathrm{NO}_{3}^{-}, \mathrm{Cl}^{-}\end{array}$ & $\mathrm{mg} \mathrm{L}^{-1}$ & $\begin{array}{l}\text { Calculate ionic strength/divalent versus } \\
\text { monovalent to determine colloidal } \\
\text { stability, specific adsorption to } \mathrm{NM} \text { and } \\
\text { soil surfaces }\left(\mathrm{PO}_{4}, \mathrm{Ca}\right) \text {, nutrient } \\
\text { availability, metal speciation }\end{array}$ & assay-specific & 71 \\
\hline DOC & $\mathrm{mg} \mathrm{C} \mathrm{L}_{1}^{-}$ & $\begin{array}{l}\text { Sterically stabilizes NMs, usually } \\
\text { increases pore water residence times }\end{array}$ & assay-specific & 21 \\
\hline porewater $\mathrm{pH}$ & & $\begin{array}{l}\text { Master variable for dissolution, surface } \\
\text { charge, speciation, .... }\end{array}$ & assay-specific & 72,73 \\
\hline Specific conductance & $\mu \mathrm{S} / \mathrm{cm}$ & $\begin{array}{l}\text { Affects NM (homo- and hetero-) } \\
\text { aggregation and deposition }\end{array}$ & $\begin{array}{l}\text { Standard, } \\
\text { measured on } \\
\text { extracted } \\
\text { porewater }\end{array}$ & 74 \\
\hline Total C, S, P, K, N & $\mathrm{mg} \mathrm{kg}^{-1}$ & $\begin{array}{l}\text { Nutrient status of sludge, potential for } \\
\text { sulfidisation and phospatization of NMs }\end{array}$ & standard & 75 \\
\hline Total toxic metals & $\mathrm{mg} \mathrm{kg}^{-1}$ & Accounting for toxic effects of metals & assay-specific & 75 \\
\hline Acid volatile sulfide & $\mathrm{mg} \mathrm{kg}^{-1}$ & Sulfidation potential of NMs & Assay-specific & 76 \\
\hline Effective porosity & & Important transport parameter in aquifers & $\begin{array}{l}\text { Modeled value } \\
\text { from tracer test }\end{array}$ & 77 \\
\hline Dispersivity & $\mathrm{m}$ & Important transport parameter in aquifers & $\begin{array}{l}\text { Modeled value } \\
\text { from tracer test }\end{array}$ & 78 \\
\hline Grain size & $\mu \mathrm{m}$ & Important transport parameter in aquifers & standard & 69 \\
\hline $\begin{array}{l}\text { Equivalent aperture of } \\
\text { fractures }\end{array}$ & $\mu \mathrm{m}$ & $\begin{array}{l}\text { Accounting for preferential flow in } \\
\text { consolidated aquifers }\end{array}$ & Assay-specific & 79 \\
\hline $\begin{array}{l}\text { Coefficient of variation of } \\
\text { fractures }\end{array}$ & $\mu \mathrm{m}$ & $\begin{array}{l}\text { Important transport parameter in } \\
\text { consolidated aquifers }\end{array}$ & Assay-specific & 79 \\
\hline Tortuosity & & $\begin{array}{l}\text { Important transport parameter in } \\
\text { consolidated aquifers }\end{array}$ & $\begin{array}{l}\text { Modeled value } \\
\text { from tracer test }\end{array}$ & 80 \\
\hline
\end{tabular}

Table 4 describes how specific parameters are descriptive of the fate and hazard of NMs in solid media. It is proposed that the key variables for assessment of NM fate and toxicity in solid media include the $\mathrm{pH}$, organic matter content, texture, extractable elements and ions, and redox potential. This is the minimum set of variables to report along with fate measurements in a standard medium, or in experimental systems to promote comparisons of behaviors of NMs in different systems. Tables 3 and 4 show how other variables are deemed descriptive of NM fate and hazard, specifically for particular media. 


\subsubsection{Considerations of benchmark media for specific parameter values}

Benchmarks solids used in nanoEHS research can be used to increase the comparability across studies. Benchmark solids must be relatively simple in structure, readily accessible, inexpensive, and consistent in their properties over time. Potential choices of standard soils and sediments, and the rationale for those choices, are provided in this section.

\section{Soils}

Further comparability could be achieved by inclusion of reference soils in studies of NM transport, transformation, bioaccumulation, and toxicity, in addition to any site-specific soils being investigated. A large variety of soils have been used as reference materials in environmental studies. Some are too simplistic for use in studies of NM transport, fate and effects, including the OECD standard soil ${ }^{81}$ as outlined below. Several well-characterized reference materials soils are being or have been sold by the National Institute of Science and Technology (e.g., Rocky Flats Soil Number 2) in quantities of up to 90 g per unit. Most soils are not readily available in sufficient quantities to support widespread adoption as reference soils for some functional assays of NM fate and effects (1-100 g), although the required quantity of soil would depend upon the assay. For the purpose of harmonizing studies of NM transport, a natural sandy soil such as Lufa 2.1 (Speyer) is widely available and is a good choice for a standard soil. ${ }^{82}$ However, restrictions on importing soils may make this a challenge for some researchers. The choice of a sandy soil was driven by the need for a soil allowing measurable NM transport parameters in column studies. For NM transformation, bioaccumulation, and toxicity studies, a natural sandy loam soil such as Lufa 2.2 (Speyer) may be a better choice. The rationale for this choice is that Lufa 2.2 represents a textural class common among agricultural soils, has been used extensively in studies of NMs and other soil contaminants (e.g. ${ }^{83,84}$ can support the organisms used in bioaccumulation and toxicity studies (e.g., plants, earthworms), and is readily available and provides reproducible soil characteristics. The properties of these soils are provided in the Supporting Information. Note that not all the recommended parameters mentioned are supplied by the provider, so additional characterization will be required for NM exposure, fate and behavior studies.

\section{Benchmark Sediments}

In contrast to soil, few examples of reference subaquatic sediments are available. Natural freshwater sediment from West Bearskin Lake, MN, USA has been used as a control sediment by the U.S. EPA for the development of benthic invertebrate toxicity assays ${ }^{85}$ and subsequently used by other researchers. ${ }^{86}$ However, the physico-chemical properties for West Bearskin Lake sediment reported by different authors vary considerably so its immediate use as a benchmark sediment may not be advisable. ${ }^{87,88}$ NIST sells estuarine sediment ${ }^{89}$ and river sediment ${ }^{90}$ at up to $70 \mathrm{~g}$ quantities per unit. Identification of a suitable reference material for sediments should be based on finding a material in sufficiently large supply that can be considered relevant in terms of the properties outlined in Table 4. This table highlights that redox-sensitive properties of solid materials are relevant for the fate of NM, particularly for dissolution and transformation, imposing additional requirements on the anoxic storage and testing of any reference material.

\section{Sludge}


Heat treated sludges, also called biosolids, are an important sink for a large proportion of NMs entering wastewater streams. Sludges are often applied to agricultural lands as a soil amendment. Reference sludges only exist as analytical chemistry standard reference materials (SRMs), such as SRM 2781 (National Institute of Standards and Technology, Gaithersburg, Maryland, USA). This material is neither intended for, nor suitable for, use as a medium in fate, transport or toxicity studies due to its complexity and variability. A number of recent studies have operated pilot scale wastewater treatment systems, utilizing local primary sludge as a feed. ${ }^{91,92}$ This approach will not be feasible for routine studies and local primary sludge and wastewater treatment processes vary considerably from location to location. Municipal biosolids are commercially available and could possibly be used as reference media. Among these products is Milorganite $\AA$, which is heat-treated sewage sludge from the municipal sewerage district of Milwaukee, Wisconsin, USA. Milorganite has been produced for over 90 years, giving some assurance of its continued availability. ${ }^{93}$ It has been used successfully in a variety of studies concerning behavior of contaminants, such as metals, after land application of sludges. ${ }^{94-97}$

\subsubsection{Key challenges and trade-offs guiding parameter and benchmark suggestions}

The greatest challenges in selecting a reference system for solids such as soils and subaquatic sediment is the complex and heterogeneous nature of those solids, and their spatial and temporal variability. Finding a reference material that captures the complexity of these systems, but can be standardized, is homogenous, and can be prepared at a reasonable cost for a sufficiently large mass is a great challenge. Clearly, there is no single soil or sediment representative for a broad set of terrestrial systems. Any reference system has to be fit for purpose. For instance, soil toxicity testing requires that the reference soil be within the ecological boundaries required by the test organisms, e.g. in terms of organic carbon content. Similarly a clay-rich soil would not be suitable for transport evaluation in column tests, because particle transport will be virtually unobservable in such soils. ${ }^{61}$ However, encompassing a variety of natural systems may increase accuracy of NM assessments, but would induce high costs in regulatory, research and industry communities.

Properly characterized reference systems as described in Table 4 are lacking for most solids of interest. It is unclear how well the proposed mixture of sand, clay and peat of the commonly selected synthetic OECD reference soil ${ }^{81}$ mimics the complex interactions that affect NM fate in natural soils. Organic matter is highly important in the control of NM behavior in soils and the OECD soil uses peat that sorbs NMs so strongly compared to other organic material ${ }^{98}$ that a reduction of peat quantity has been advised for OECD testing of NMs. ${ }^{99}$ Moreover, saturated column experiments cannot be done in the OECD soil because of the high clay content $(20 \%)^{65}$, 100 and using this reference soil has been shown to lead to variability between toxicity assays. ${ }^{101}$

Interfaces with other media. Soils, sediments, aquifers and sludges all interface with different environmental media, to which NMs can transfer. A full assessment of the fate and impacts of NMs in the environment requires the use of a combination of media types described in this paper. For instance, biosolids application in agricultural soil are increasingly studied as one of the main routes of soil exposure to NMs. Sediment and aquifer experiments need to be conducted with a relevant aquatic media with respect with the ecosystem studied (i.e. freshwater, estuarine, marine water media). Soil, sediment or sludges are also used in biological tests simulating exposure to NMs through ingestion (simulated body fluids media for various organisms) or 
contact (simulated surface contact media). In this harmonizing process, reporting of the key parameters (Table 4) and use of the recommended media proposed here should be considered in all experiments involving soil, sediment, aquifers or sludge media.

\subsection{Biological Media}

\subsubsection{Context and background}

Assessment of the potential risks of NMs requires understanding of both exposure and hazard. While the aquatic and solid media considerations have focused primarily on the fate and behaviors aspects, which determine the amount and form of NMs that remain bioavailable for uptake by organisms in these environmental compartments, assessment of NM toxicity requires harmonization of biological test media also to ensure comparability of data sets. Hazard assessment is dependent on availability of the test species (e.g. NM) in an appropriate form and medium for the particular exposure route being assessed, be that exposure via inhalation, via ingestion (including via the food chain) or via dermal contact.

Thus far in the manuscript, the focus has been on environmental matrices into which NMs may be released along a product's life cycle or as a result of disposal at the end of life. However, many applications of NMs are being developed for direct contact with humans, including nanomedicines and food contact materials, for example, and as such media specifications for biological testing in humans are needed, including for example, models of lung surfactant fluids and digestive foods. Thus, this section provides considerations on the key parameters that need to be specified for a range of hazard testing scenarios as part of the overall goal of harmonizing NMs characterization.

Given the high surface energy and "stickiness" of NM, it is now widely agreed that biological or (eco)toxicological assessment of NMs in the absence of appropriate biomolecules in the medium leads to non-biologically relevant effects related to physical damage of membranes rather than real biological effects. Indeed, in the absence of such biomolecules in the medium, NMs rapidly pull proteins from the cellular membrane and "acquire" a coating of biomolecules, or corona, ${ }^{102}$ and indeed cells ${ }^{103}$ and organisms ${ }^{104}$ have been shown to condition their medium and surroundings leading to evolution of the NM corona and altered toxicological profiles. What is less agreed, or less consistent, however, is what the appropriate biomolecules to add to media are and how much should be added, in part because of ongoing challenges in terms of in vitro-in vivo correlations, ${ }^{105,106}$ and in part because the biological macromolecules present naturally depend greatly on the route of exposure. Thus, the first biomolecules encountered during inhalation exposure include salivary proteins potentially, and lung surfactant fluids certainly. ${ }^{107,} 108$ Ingestion will also lead to contact with saliva, followed by contact with gastric fluids, duodenal fluids and potentially translocate across the gut-blood barrier. ${ }^{109}$

Although many experimental studies describe NM coronas and correlations to uptake and impact, a comprehensive picture is still missing, in particular due to the multitude of different scenarios under which experiments have been performed. ${ }^{110}$ Thus, the goal of this section of the paper was to reach some consensus regarding the appropriate biological media for testing of toxicological and ecotoxicological impacts of NM, including providing recommendations for 
some specific biofluids where sufficient confidence exists as to their applicability and broad relevance. Where possible and appropriate, the media recommendations for ecotoxicity testing are aligned with the recommended media from the aquatic and solid compartments defined above, since this streamlines experimental approaches and facilitates maximum integration of the exposure and hazard data for risk assessment.

\subsubsection{Recommended media and parameters}

Given the very broad scope of the topic biological testing media and the range of organisms each with distinct physiologies, the group has quite some considerable debate in terms of prioritizing which sub-systems as being most important to address. Our first categorization was between submerged exposure scenarios (i.e. NMs in a liquid medium exposed to an organism surface) which constituted the majority of cases, versus an air-surface exposure scenario such as mimicking the lung-air (or gill for some aquatic organisms) barrier (the so called Air-liquid interfaces) as well as NMs in contact with skin, eyes, plant leaves etc. as shown in Table 5. Within those two broad categories, we first describe the characterization requirements for the most well-studied cases (typically human toxicology) and then consider any additional considerations / differences for ecotoxicity in the aquatic and solid compartments.

The initial long-list of parameters that we identified as being critical for biological media consisted of 17 items, which further discussion lead us to categorize as being either Media considerations (relevant to the current paper) or Assay considerations (not in the scope of the current paper), as illustrated schematically in Figure 1. In the subsequent discussion, only those characteristics identified as being media specific are included in the specifications of the media, and assay-specific characteristics are not addressed.

Table 5: Minimum set of parameters recommended for inter-study comparison of the fate and effects of nanomaterials in biological media

\begin{tabular}{|c|c|c|c|}
\hline \multicolumn{2}{|c|}{ Media type } & Primary Measurements & Secondary Measurements \\
\hline \multirow{3}{*}{ 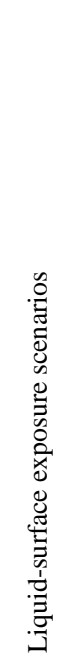 } & Mammalian culture medium & $\begin{array}{l}\text { - } \mathrm{pH} \\
\text { - Ionic Strength } \\
\text { - Ionic content } \\
\text { - } \% \text { serum } \\
\text { - Source of serum (Bovine calf, mouse, } \\
\text { rabbit, human etc.) } \\
\text { - whether serum was heat inactivated or } \\
\text { not }\end{array}$ & $\begin{array}{l}\text { - Relative Humidity } \\
\text { - } \% \mathrm{CO}_{2}\end{array}$ \\
\hline & Aquatic organism culture media & $\begin{array}{l}\text { - } \mathrm{pH} \\
\text { - Ionic strength } \\
\text { - Major cations (e.g. hardness) } \\
\text { - Major anions (e.g. alkalinity) } \\
\text { - } \text { DO }\end{array}$ & $\begin{array}{l}\text { - Ionic content (e.g. monovalent, } \\
\text { divalent, } \mathrm{Cl}^{-}, \mathrm{S}^{-} \text {etc.) } \\
\text { - Food type and amount } \\
\text { - NOM or other biomolecules added } \\
\text { - concentration, source }\end{array}$ \\
\hline & Microbial medium & $\begin{array}{l}\text { - } \mathrm{pH} \\
\text { - Ionic Strength }\end{array}$ & $\begin{array}{l}\text { - Major cations (e.g. hardness) } \\
\text { - Major anions (e.g. alkalinity) }\end{array}$ \\
\hline
\end{tabular}




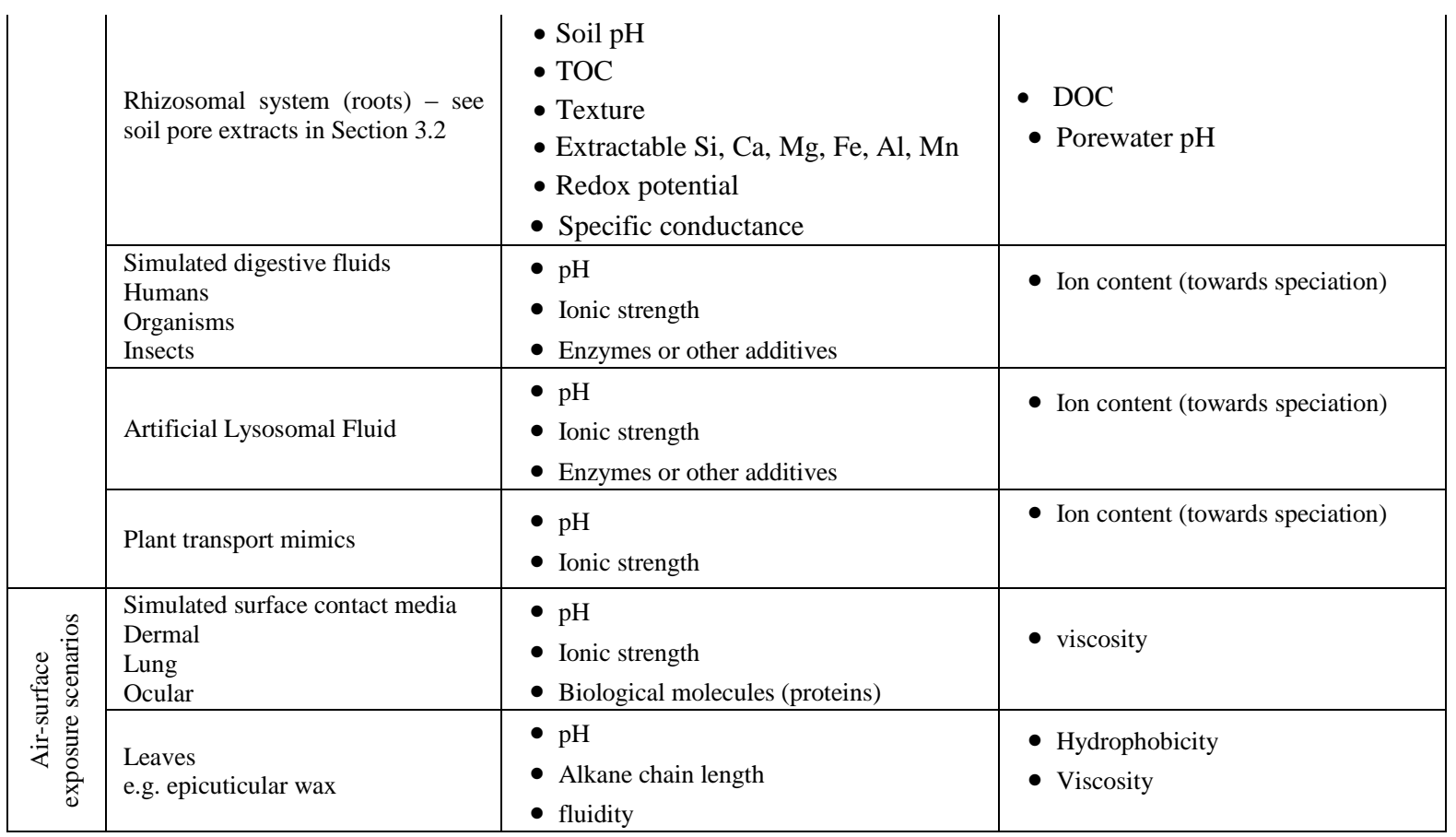

\section{Discussion of primary parameters.}

pH: Most normal mammalian cell lines grow well at $\mathrm{pH} 7.4$, with very little variability among different cell strains. However, some transformed cell lines have been shown to grow better in slightly more acidic environments ( $\mathrm{pH} 7.0$ to 7.4), and some normal fibroblast cell lines prefer a slightly more basic environments ( $\mathrm{pH} 7.4$ to 7.7). Insect cell lines such as Sf9 and Sf21 grow optimally at $\mathrm{pH} 6.2 .^{111}$ Bacterial testing is also routinely performed at $\mathrm{pH} 7.4$, with OCED 301 stating an optimal pH of $7.4 \pm 0.2$. Similarly, most organisms have an optimal $\mathrm{pH}$ range, and media derived for these usually sit in physiological ranges. For example, Daphnia have been found to have optimal survival, growth and reproduction at $\mathrm{pHs}$ in the range 7.9 to $8.3{ }^{112}$ Thus, $\mathrm{pH}$ is an essential parameter for all liquid media types, as physiological changes related to environmental stress will arise when organisms are outside of their optimal $\mathrm{pH}$ range, which will compromise any subsequent exposure or hazard assessments. In the case of simulated fluids, such as digestive fluids, or Artificial lysosomal fluids (ALF), these are specific fluids where an unusual $\mathrm{pH}$ is required to achieve a specific function, and thus assessment of the effectiveness of this function can only be done at the relevant $\mathrm{pH}$.

Ionic Strength and Ionic Content: The physiological ionic strength is between 100 to 200 $\mathrm{mmol} / \mathrm{L} \mathrm{KCl}$ or $\mathrm{NaCl}$. The growth medium controls the $\mathrm{pH}$ of the culture and buffers the cells in culture against changes in the $\mathrm{pH}$. Usually, this buffering is achieved by including an organic (e.g., HEPES) or $\mathrm{CO}_{2}$-bicarbonate based buffer. Biomolecule protonisation and deprotonisation (e.g. binding and conversion of a substrate by the enzyme) depend on the ionic composition of the surrounding medium. At $\mathrm{pH} 7.5$, phosphate buffers add about $7 \times$ more ions to the medium than zwitterionic Tricine (nitrogen containing) buffers. ${ }^{113}$ 
Serum percentage, source of serum, and whether serum was heat inactivated: This consideration is quite specific to mammalian cell culture, where serum is routinely utilized as a food source for cells. Depending on the cell type, the amount of serum (typically foetal bovine serum, FBS) ranges between $2 \%$ (e.g. for blood-brain barrier cells) to $20 \%$ often recommended to speed up the growth of e.g. $\mathrm{CaCO}_{2}$ cells, with $10 \%$ being somewhat the standard. However, with NMs, the ratio of the NM surface to the amount of proteins present can have an important role in terms of proteins bound in the corona: for some NMs more proteins available results in thicker coronas of the same composition, while for others quite different coronas occur at different surface area: FBS ratios. ${ }^{114,115}$ Increasing the amount of extracellular proteins (serum) to $100 \%$ rather than the usual $10 \%$ dramatically reduced the uptake and the toxicity observed, with no change in the effective size or stability of the NM dispersions. ${ }^{115}$ So there is potentially a case to be made to move to high serum concentrations as they might be more representative of in vivo environments, and thus also facilitate improved in vitro - in vivo correlations.

The source of the serum (fetal bovine, fetal calf, or other animal sera such as mouse, rat, rabbit or horse, as well as human) is an important consideration, as the different sera have been shown to result in quite different corona compositions and differential cellular uptake of the particles and thus differential toxicity induction in cells. ${ }^{115,116}$ For example, lower rates of uptake of the same NMs by the same cells were observed with the NMs/cells incubated in human serum compared to bovine serum (for 50nm amine-modified polystyrene NMs in A549 cells). ${ }^{115}$ Heat inactivation or not of the FBS has also been shown to affect the NM corona composition, ${ }^{117}$ and thus should be reported.

\section{Discussion of secondary parameters.}

$\mathrm{CO}_{2}$ Levels: Because the $\mathrm{pH}$ of the medium is dependent on the delicate balance of dissolved carbon dioxide $\left(\mathrm{CO}_{2}\right)$ and bicarbonate $\left(\mathrm{HCO}_{3}{ }^{-}\right)$, changes in the atmospheric $\mathrm{CO}_{2}$ can alter the $\mathrm{pH}$ of the medium. Therefore, it is necessary to use exogenous $\mathrm{CO}_{2}$ when using media buffered with a $\mathrm{CO}_{2}$-bicarbonate based buffer, especially if the cells are cultured in open dishes or transformed cell lines are cultured at high concentrations. Most researchers use $5 \%$ to $7 \% \mathrm{CO}_{2}$ in air, however, each medium has a recommended $\mathrm{CO}_{2}$ tension and bicarbonate concentration to achieve the correct $\mathrm{pH}$.

Relative Humidity: Using an incubator humidity of $85 \%$ to $95 \%$ limits evaporation of water from cell culture media. Evaporation can substantially raise the media concentrations of salts, minerals, etc., potentially resulting in toxicity and cell death. High humidity is the most difficult condition to maintain but is critically important, as evaporation is 4 times faster at $80 \%$ humidity than at $>93 \% .^{118}$

Table 6. Units, rationale and references for recommended parameters to characterize biological media

\begin{tabular}{|l|l|l|l|l|l|}
\hline \multicolumn{1}{|c|}{ Parameters } & Units & \multicolumn{1}{|c|}{ Rationale } & Method Type & \multicolumn{1}{c|}{$\begin{array}{l}\text { Media } \\
\text { Types }\end{array}$} & \multicolumn{1}{c|}{ Reference } \\
\hline $\mathrm{pH}$ & & $\begin{array}{l}\text { Many biomolecules are pH sensitive; } \\
\text { different biological compartments have } \\
\text { specific pHs for optimal functionality, e.g. } \\
\text { digestive tracts are typically acidic to } \\
\text { support breakdown of the food and release } \\
\text { the nutrients for adsorption. }\end{array}$ & Standard & $\begin{array}{l}\text { and liquid } \\
\text { media for } \\
\text { toxicity \& } \\
\text { NM fate } \\
\text { assessment }\end{array}$ & 18 \\
\hline Ionic strength & $\mathrm{mM}$ & $\begin{array}{l}\text { Calculate from either reagent addition or } \\
\text { from conductivity measurements }\end{array}$ & Standard & $\begin{array}{l}\text { All liquid } \\
\text { media }\end{array}$ & 19 \\
\hline
\end{tabular}




\begin{tabular}{|c|c|c|c|c|c|}
\hline $\mathrm{CO}_{2}$ concentration & $\%$ & & Assay-Specific & $\begin{array}{l}\text { Tissue / } \\
\text { cell culture }\end{array}$ & 119 \\
\hline DO concentration & $\%$ & $\begin{array}{l}\text { Important for both biological growth and } \\
\text { NM behavior }\end{array}$ & Standard & $\begin{array}{l}\text { All liquid } \\
\text { media }\end{array}$ & 21 \\
\hline $\begin{array}{l}\text { Relevant minimum } \\
\text { biomolecular components \& } \\
\text { relative concentration }\end{array}$ & $\%$ & $\begin{array}{l}\text { Relative concentration (e.g. concentration } \\
\text { to surface area). }\end{array}$ & Assay-Specific & $\begin{array}{l}\text { Tissue / } \\
\text { Cell } \\
\text { Culture }\end{array}$ & \\
\hline Major cations & $\mathrm{mM}$ & $\begin{array}{l}\text { Hardness - needs to be suitable for the } \\
\text { organism being tested, affects NM } \\
\text { stability and size distribution }\end{array}$ & Assay-Specific & $\begin{array}{l}\text { Aquatic \& } \\
\text { soil } \\
\text { organism } \\
\text { test media }\end{array}$ & 20 \\
\hline Major anions & $\mathrm{mM}$ & $\begin{array}{l}\text { Alkalinity - needs to be suitable for the } \\
\text { organism being tested, affects NM } \\
\text { stability and size distribution }\end{array}$ & Assay-Specific & $\begin{array}{l}\text { Aquatic \& } \\
\text { soil } \\
\text { organism } \\
\text { test media }\end{array}$ & 20 \\
\hline DOC & $\mathrm{mg} / \mathrm{L}$ & $\begin{array}{l}\text { Important for both biological growth and } \\
\text { NM behavior }\end{array}$ & Standard & $\begin{array}{l}\text { All liquid } \\
\text { media }\end{array}$ & 21 \\
\hline Growth factors & $\mathrm{mg} / \mathrm{L}$ & Modulators and antibiotics / antimiotics & Assay-Specific & Cell culture & \\
\hline
\end{tabular}

\subsubsection{Considerations of benchmark media for specific parameter values}

Tissue medium (submerged culture)

The goal here was to address both in vitro and in vivo studies and cover not just human and mammalian approaches but also aquatic, rhizosomal (soil) and microbial considerations, including in complex communities such as in waste water treatment plants. For simplicity, each is treated in turn, starting with in vitro human and mammalian and progressing to other cellular models (e.g. bacterial, algae etc.) and then to in vivo approaches.

Mammalian culture medium. FBS is a ubiquitously used essential supplement in cell culture media, for both human and mammalian cells. However, there are serious scientific and ethical concerns about the use of FBS regarding its harvest and production. ${ }^{120}$ Efforts are underway to develop serum-free cell cultures in other fields, mostly as means to harmonize or reduce the inherent variability from animal-derived compounds. There are various degrees of chemical definition, e.g. serum-free (SF), animal-derived component free or chemically defined, and the type of medium, e.g. basal media, medium supplements, or full replacement media. ${ }^{120}$ However, these are far from being standardized, and are thus not discussed further here.

The large reactive surface area of NMs makes the addition of biomolecules to the medium essential in order to avoid physical damage of membranes. Thus, SF conditions may not be feasible for use with NMs, unless other synthetic macromolecules can be substituted instead to bind to the NMs and passivate their surface. However, this would also reduce the potential for specific cell surface receptor engagement by the NMs and would thus reduce the realism of the exposure. However, this could be considered a "worst case" scenario and may lead to more reproducible results, both of which may be preferred over increased realism depending upon the purpose of the experiment. There is a school of thought that suggests that the serum should be matched to the cell type - human sera for human cells, mouse sera for mouse cells etc., in order not to have impacts from non-self immune recognition that might be mis-interpreted as NM effects. $^{121}$ However, very limited work has been done to demonstrate or validate this, and as such no recommendation to this end can be made at this point. A related issue is that of what are the appropriate biomolecules for cells / tissues developed to mimic specific routes of entry - for 
example, the appropriateness of serum for lung cells or gut cells is entirely questionable, although in many protocols is included. Thus, perhaps the harmonization could be on the fact that suitable biomolecules need to be present, and they need to be matched appropriately to the cell model and the research question. Some overlap such as use of FBS might be required in parallel though, at least in the interim, to allow comparability across approaches.

In light of these considerations, our recommendation for cell culture medium is a commonly applied medium, Dulbecco's Modified Eagle's Medium (DMEM), which is a modification of Basal Medium Eagle (BME) that contains a four-fold higher concentration of amino acids and vitamins, as well as additional supplementary components. DMEM requires supplementation with $1 \%$ to $5 \% \mathrm{FBS}$ and $4 \mathrm{mmol} / \mathrm{L}$ L-glutamine supplement. The FBS concentration must be optimized for each cell line to obtain maximum serum reduction. DMEM uses a sodium bicarbonate buffer system $(3.7 \mathrm{~g} / \mathrm{L})$, and therefore requires a $5 \%$ to $10 \% \mathrm{CO}_{2}$ environment to maintain physiological pH. See Table SI.3.2 for full details.

\section{Simulated digestive fluids (human):}

Simulated saliva. Recent studies that have simulated saliva fluid lack cohesiveness of background media constituents. It is challenging to duplicate human saliva because (a) it is excreted from several different glands at different volumes, (b) its contents can vary at different times during the day, and (c) it can be influenced by the diet. ${ }^{122}$ In 2001, a critical review was published on reported synthetic saliva used for in vitro studies between 1931 and $1996(\mathrm{n}=60){ }^{123}$ The review condensed the parameters from each source and recommended a standard saliva gastric fluid medium that consisted of minimal nutrients and no organic proteins. Additional biomolecules (i.e. mucin, amylase) can be added, but their dose is dependent on the specificity of the concern at hand (i.e. smoking, drug delivery). Additionally, the $\mathrm{pH}$ can be altered slightly depending on the consumption of dietary acids or some dietary drugs. For all systems modified to account for unique parameters, it is recommended that they are also reported. Below is a table describing this simulated saliva medium that we endorse for NM harmonization purposes. See Table SI.3.3 for further details of the recommended benchmark for simulated saliva.

Gastric fluids. Here we define a specific model simulated gastric fluid, closely resembling the fluids found in the stomach of mammals. ${ }^{124}$ As with the other model simulated biological fluids, they are parameterized using the minimum reporting standards outlined in Table 3 . In the development of a model gastric fluid, careful consideration must be given to the behavior of $\mathrm{NMs}$ in such a medium. For that reason, we decided that the frequently used $0.07 \mathrm{M} \mathrm{HCl}$ solution is insufficient to accurately capture NM behaviors such as aggregation state, deposition kinetics, and transformation among others, all of which will strongly impact nearly any nanoparticle assay run in the medium. ${ }^{86}$ Therefore, the current proposed standard medium includes a small number of gastric proteins in addition to the proper ionic strength expected in a gastric fluid. This has been adapted from model gastric fluids reported previously with some adaptation in order to include a more complete picture of relevant biomolecules in a fasted state. Adjustments for fed states include higher $\mathrm{pH}$ and ionic strength. ${ }^{125}$ See Table SI.3.4 for our recommendation in terms of a benchmark for simulated gastric fluid. 
Simulated digestive fluids for fish and other organisms. It appears from a cursory review of the literature (I will need to search more) that simulated gut or digestive fluids are significantly less widely used in environmental organisms. A couple of recipes for simulated fish (carp) digestive fluid have been identified, one of which was applied to assess the adsorption and desorption of the pesticide pentachlorophenol in the presence of multi-walled carbon nanotubes. ${ }^{126}$ The simulated digestive fluid consisted of $0.12 \mathrm{~mol} \mathrm{~L}-1 \mathrm{NaCl}, 0.02 \mathrm{~mol} \mathrm{~L}-1 \mathrm{Na}_{2} \mathrm{CO}^{3}, 200 \mathrm{mg} \mathrm{L}^{-1}$ bile salt, $\mathrm{pH}=7.5$ and was assessed without or with pancreatin $(100 \mathrm{mg} \mathrm{L}-1)$ to imitate digestive fluids under different ingestion conditions ${ }^{127,}{ }^{128}$ (supposedly in carp although closer inspection of the references cited indicated that the original recipes were for simulated human digestive fluids). A very detailed analysis of digestion processes in fish is provided in the report of the FAO/UNDP Aquaculture Development and Coordination Programme Training Course in Fish Feed Technology at the College of Fisheries which could form the basis of such a protocol. ${ }^{129}$

A chemically defined artificial larval midgut fluid capable of activating Bacillus thuringiensis var. kurstaki HD-1 spores has been reported. ${ }^{130}$ Through study of its individual components, and of modified Manduca sexta (tobacco hornworm) midgut fluid, it was determined that the principal activator of these spores in native midgut fluid is alkaline $\mathrm{pH}$, with little or no contribution from either proteases or reductants. ${ }^{130}$ It would thus seem like an area where more research is needed, and as such as we are not making any recommendations regarding simulated digestive fluids for non-human organisms at this time. However, minimum reporting guidelines put forth here in Table 6 should also be followed for non-human organisms.

Blood. While both plasma and serum are obtained from blood, their compositions are very different. ${ }^{131}$ The preparation of plasma from blood involves the addition of anti-coagulant reagents, followed by centrifugation to remove the blood cells. In contrast, serum preparation involves coagulating the blood thus depleting the serum of coagulation factors, such as fibrinogen, which lowers its protein concentration. ${ }^{132}$ Human plasma has been demonstrated to mimic the composition of the blood environment more accurately than human serum, so the use of plasma, and not serum, has been suggested as being essential for in vitro analysis of the protein corona. ${ }^{131}$

\section{Simulated surface contact media}

Simulated biological fluids have been used traditionally in the pharmaceutical and biomedical industries for testing and defining the dosage of drugs. ${ }^{125}$ We recommend the use of these established media to investigate the physico-chemical behavior of NMs at the point of contact with biological systems and for quantifying the potential absorption of NMs by those systems.

Pulmonary fluids. Here we endorse an existing simulated pulmonary surfactant fluid ${ }^{133}$ for use as a model medium in NM inhalation exposure scenarios. As with the other proposed simulated biological fluids, the composition was chosen for its ability to capture NM behavior in complex biological systems, which will depend on not just the quantity of surfactant in the fluid but on its composition and relative concentrations. This has been observed in several studies, in which protein or natural amphiphiles exhibited differential binding for NM surfaces. ${ }^{134,}{ }^{135}$ While the entire spectrum of possible pulmonary proteins and surfactants is not included here for the sake of simplicity in preparation and analysis, we believe it to be a representative minimum set of relevant biomolecules. 
Air-liquid interfaces (ALI). When considering the various routes of exposure of NMs to multicellular organisms, especially mammals, wet (mucosal) surfaces and ALI are of special interest as a first point of contact (e.g., skin, lungs, eyes, mouth and digestive tract). Those surfaces can be modeled through the use of simulated biological fluids. Our recommended ALI composition is given in Table SI.3.5.

Simulated leaf surfaces (e.g. for nanopesticide formulations ${ }^{136}$ ). This is an emerging area for NMs with no studies found to date, however simulated leaf surfaces have been prepared for chemical testing. For example, hydrocarbon wax and beeswax were compared by forming surfaces on stainless steel plates, with a target wax coverage of $1 \mathrm{mg} \mathrm{cm}^{-2}$. This mass of wax was dissolved in $25 \mathrm{ml}$ of dichloromethane at $40{ }^{\circ} \mathrm{C}$ then decanted in 3 aliquots and evenly sprayed onto the foil-covered plate via a nebulizer. The actual mass of wax on the foil surface was determined by weighing the wax-coated foil following spraying. ${ }^{136}$ Some additional work would be needed in order to assess the suitability of this approach for assessing NM interactions, and thus no recommendation is made at this point.

\subsubsection{Key challenges and trade-offs guiding parameter and benchmark suggestions}

The major challenge in this group was the sheer diversity of biological fluids with which NMs might potentially come into contact, even just from the human health perspective, and which might influence the NMs properties and impacts. For humans this includes (but is not limited to) saliva, gastric juice, duodenal juices, lung surfactants, sweat, blood (serum or plasma), lymph fluids, cerebrospinal fluids, ocular fluids, cytosolic fluids, lysosomal fluid etc. Models for each of these exist, and have been developed across an array of disciplines, most independent of studies with NMs. Considering the potential routes of entry for NMs into the body, each of the barriers include also some mucus or biomolecules that also influence the NM transport, such as sebum on skin, nasal mucus in the nose, and the surfactant layers in the lung and can interact with NMs. For aquatic and soil organisms, the major consideration has traditionally been the natural organic matter components, but it is increasingly understood that organisms secrete biomolecules into their surroundings as part of food web signaling and stress responses, ${ }^{104}$ which also need to be considered in the design of optimal media for ecotoxicological studies.

The main tradeoff in selection and recommendation of media is that not all have been validated for use with NMs, and the need to ensure that suitable biomolecules are included as appropriate, to reduce the physical damage associated with the high surface area of NMs, and ensure more realistic exposure conditions, such as NMs would encounter in realistic release or exposure scenarios, such that experimental artefacts are reduced as much as possible. In several cases it was not yet possible to make recommendations, but it is clear that the approach utilized for selection of DMEM, simulated saliva and other digestive fluids and for pulmonary fluids can be applied to a wide range of biological mimics.

\subsection{Engineered waste systems}

\subsubsection{Context and background}


In addition to natural environments, there are a number of engineered systems that naturally occurring and engineered NMs will enter and potentially accumulate in, and in which it will be important to understand and forecast their behavior and impacts. For this paper, the focus is on waste treatment and holding systems that will receive an influx of engineered NMs in the course of their life cycles. These media types include aquatic, solid, and biological aspects which are addressed separately here because they are not naturally occurring, and their properties and inputs are in many cases controlled by human decisions. The purpose of waste treatment systems or engineered systems is the elimination or removal of unwanted components from any waste streams. Processes occurring in managed waste facilities / engineered systems such as heteroaggreagtion, dissolution and chemical transformation may lead to (incidential) removal of NMs from waste streams. Current waste treatment systems are not designed to remove NMs, and thus NMs may pass through these barriers and be released into aquatic environments (e.g. surface water, groundwater), into solid phases, or into the atmosphere.

\subsubsection{Recommended media and parameters}

The $\mathrm{OECD}^{137}$ has identified four waste treatment systems as being most relevant for examining the possible impacts of nanowastes: wastewater treatment, incineration, landfilling and recycling. The overall goal of all waste treatment systems is to remove / separate unwanted components from waste streams, but individual facilities operate according to very different principles. High temperatures during waste / sludge incineration result in the combustion of organic materials contained in the waste material and an enrichment of inorganic compounds in the bottom and fly ash. During the activated sludge processing, organic materials are biologically degraded and inorganic materials are separated from the wastewater by sedimentation in the secondary clarifier. Considerable variability also exists within the same type of waste treatment system, e.g. the water chemical parameters of landfill leachates vary strongly depending on the landfill type and age. It is thus challenging to balance the variability between systems and the variability within systems. Based on the life cycle perspective of NM and in accordance with the OECD report on nanowaste, ${ }^{137}$ we identified four systems (activated sludge, treated wastewater, sewage sludge ash, and landfill leachate ( as eluted into liquid phase from municipal solid waste )) as most relevant.

Incineration is a very important treatment process, which affects the form and 'availability' of NMs. Werther and Ogada ${ }^{138}$ defined three categories of thermal sludge treatment: i) monoincineration ii) co-combustion and iii) alternative thermal processes (pyrolysis, gasification). Each thermal process will produce ash with different chemical and physical properties. Thermal processes are prone to modify the physical state of NMs as a function of the exact temperature and the thermal stability of the NMs. Carbon NMs are a particular concern since the temperature reached during the incineration may lead to only partial combustion and transformation of carbon-based NMs. ${ }^{139-142}$ Thermally unstable metal-based NMs will transform into other chemical species but more refractive materials (e.g. $\mathrm{Al}_{2} \mathrm{O}_{3}$ and $\mathrm{TiO}_{2}$ ) will remain chemically unchanged. ${ }^{139,141,143}$ Sewage sludge incineration in fluidized bed reactors (mono-incineration) is becoming increasingly popular. Approximately $30 \%$ of the initial solids content of sewage sludge consists of inorganic matter which will remain as sewage sludge ash. After the combustion process, the fate of NMs will depend on the recycling and recovery route of sewage sludge ash. Sewage sludge ash can be used during sintering of materials to form brick for instance, or in cementitious materials. This may lead to NM incorporation into solid matrices. 
The recovery of $\mathrm{P}$ from sewage sludge ash, however, using acid leaching may result in NM release from the ash. It was shown that fluidized bed incinerators can generate ash with a very low variation of chemical composition. Indeed Anderson and Skerratt ${ }^{95}$ analyzed 18 ash samples collected during a period that covered six weeks from one fluidized bed incinerator in the UK. The variability, expressed as standard deviation of $\mathrm{Si}, \mathrm{Ca}, \mathrm{Fe}, \mathrm{Al}$ and $\mathrm{P}$ concentrations, was in $0,2-1,2 \%$ range, but this does not necessarily indicate that NMs were present. Results from Krueger et al ${ }^{144}$ including 252 sewage sludge ash samples from 24 of the 26 sewage sludge mono-incinerator facilities in Germany also indicated limited variation in the chemical composition of the ash samples. Due to the relatively small variations in sewage sludge ash, these ashes may be appropriate for standardization purpose, but no standardized sewage sludge ash exists, yet. However, using the sewage sludge ash as a medium to conduct experiments addressing the fate of NM (e.g. released in column experiments) is not very meaningful, as directly adding the NMs to sewage sludge ash omits the high temperature process leading to a fundamentally different incorporation of NMs into the ash matrix. We therefore did not consider sewage sludge ash as a useful medium in the context of this paper. Nevertheless, relevant media associated with wastewater treatment and landfilling can be defined more specifically (Table 7).

Table 7: Minimum set of parameters recommended for inter-study comparison of the fate and effects of nanomaterials in engineered waste media

\begin{tabular}{|c|c|c|}
\hline Media type & Primary Measurements & Secondary Measurements \\
\hline $\begin{array}{l}\text { Activated } \\
\text { sludge }\end{array}$ & $\begin{array}{l}\text { - } \mathrm{pH} \\
\text { - Total Suspended Solids (TSS) } \\
\text { - } \text { DOC } \\
\text { - Electrical conductivity } \\
\text { - Sludge volume index (SVI) }\end{array}$ & $\begin{array}{l}\text { - } \mathrm{TOC} \\
\text { - } \mathrm{O}_{2} \\
\text { - } \mathrm{Major} \text { cations (e.g. } \mathrm{K}^{+}, \mathrm{Na}^{+}, \mathrm{Ca}^{2+} \text {, } \\
\mathrm{Mg}^{2+} \text { ) } \\
\left.\text { - } \text { Major anions (e.g., } \mathrm{Cl}^{-}, \mathrm{SO}_{4}{ }^{2-}\right) \\
\text { - } \text { Nitrate }\left(\mathrm{NO}_{3}{ }^{-}\right) \\
\text {- } \text { Ammonium }\left(\mathrm{NH}_{4}^{+}\right)\end{array}$ \\
\hline $\begin{array}{l}\text { Treated } \\
\text { wastewater }\end{array}$ & $\begin{array}{l}\text { - } \mathrm{pH} \\
\text { - } \mathrm{TSS} \\
\text { - } \mathrm{DOC} \\
\text { - Electrical conductivity }\end{array}$ & $\begin{array}{l}\text { - } \text { TOC } \\
\text { - } \text { Major cations (e.g. } \mathrm{K}^{+}, \mathrm{Na}^{+}, \mathrm{Ca}^{2+} \text {, } \\
\left.\mathrm{Mg}^{2+}\right) \\
\left.\text { - } \text { Major anions (e.g., } \mathrm{Cl}^{-}, \mathrm{SO}_{4}{ }^{2-}\right) \\
\text { - Nitrate }\left(\mathrm{NO}_{3}{ }^{-}\right)\end{array}$ \\
\hline $\begin{array}{l}\text { Landfill } \\
\text { leachate }\end{array}$ & $\begin{array}{l}\text { - } \mathrm{pH} \\
\text { - } \mathrm{TSS} \\
\text { - } \mathrm{DOC} \\
\text { - Electrical conductivity } \\
\text { - Redox potential }\end{array}$ & $\begin{array}{l}\text { - } \mathrm{O}_{2} \\
\text { - } \mathrm{TOC} \\
\text { - Major cations }\left(\mathrm{Ca}^{2+}, \mathrm{Mg}^{2+},\right) \\
\text { - Major Anions }\left(\mathrm{SO}_{4}{ }^{2-}, \mathrm{Cl}^{-}, \mathrm{NO}_{3}{ }^{-}\right)\end{array}$ \\
\hline
\end{tabular}

Discussion of primary parameters:

For all three media, $\mathrm{pH}$, TSS, DOC and the electrical conductivity were considered as key parameters which should be reported. In addition, the redox potential should be reported in landfill leachates. From the measurement of the electrical conductivity, the ionic strength and the total dissolved solids can be estimated based on well-established correlations between these parameters. ${ }^{145}$ The redox potential is a crucial parameter for predicting the speciation of metals 
in aqueous environments (see Soils and Sediments section discussion). Therefore, the redox potential will be particularly be important to assess the fate $\mathrm{Cu}, \mathrm{Zn}$, and $\mathrm{Ag}$ NMs. Nevertheless, it should be pointed out that speciation calculations are only applicable under thermodynamic equilibrium conditions, which may not be reached in the media described in this section.

Discussion of secondary parameters:

Apart from the primary parameters listed above, we have identified a set of secondary parameters, which should be reported if possible. Nitrate and ammonia concentrations are of key importance for activated sludge media and provide information about the performance of a wastewater treatment plant. These values should therefore be measured. Furthermore, the oxygen concentration is important and informs about processes (nitrification / denitrification) that are occurring in the sludge. Although it is possible to calculate the ionic strength based on empirical correlations with the electrical conductivity, measurements of major cations and anions would provide more reliable data on the ionic strength of the respective media. TOC content provides information about the condition of the sewage sludge, and when measured in the treated water can be used as a measure of the performance of the wastewater treatment plant. Oxygen concentrations measured in landfill leachates are useful to assess the conditions in the landfill (oxic vs. anoxic), which will have a direct impact on NM transformations including dissolution, oxidation, and redox activity. ${ }^{146}$ For example, anoxic conditions will limit dissolution of some NMs (e.g., AgNPs), while the redox activity will also impact the extent to which the speciation of other NMs such as cerium oxide NMs occurs. ${ }^{13}$

Table 8. Units, rationale and references for recommended parameters to characterize engineered waste media

\begin{tabular}{|c|c|c|c|c|c|}
\hline Parameters & Units & Rationale & $\begin{array}{l}\text { Method } \\
\text { Type }\end{array}$ & $\begin{array}{l}\text { Media } \\
\text { Types }\end{array}$ & Reference \\
\hline $\mathrm{pH}$ & & $\begin{array}{l}\text { Indication of the state of the associated } \\
\text { wastewater treatment plant }{ }^{1,2} \text {. It is } \\
\text { important to assess conditions in the } \\
\text { landfill and the stability of inorganic } \\
\text { compounds (e.g. dissolution or } \\
\text { precipitation of mineral phases) }{ }^{3}\end{array}$ & Standard & $1,2,3$ & 66,73 \\
\hline TSS & $\mathrm{mg} \mathrm{L}^{-1}$ & $\begin{array}{l}\text { Indication of the state of the associated } \\
\text { wastewater treatment plant }{ }^{1,2} \text {. Useful for } \\
\text { comparability between different field sites } \\
\text { / synthetic mixtures }{ }^{3}\end{array}$ & Standard & $1,2,3$ & 25 \\
\hline DOC & $\mathrm{mg} \mathrm{L}^{-1}$ & ${ }_{3}^{\text {Influence on colloidal stabilities of } \mathrm{NMs}{ }^{1-}}$ & Standard & $1,2,3$ & 21,68 \\
\hline Electrical conductivity & $\mu \mathrm{S} \mathrm{cm}^{-1}$ & $\begin{array}{l}\text { Allows estimation of total dissolved solids } \\
\text { and ionic strength (key parameter for } \\
\text { stability calculations) }\end{array}$ & Standard & $1,2,3$ & 19 \\
\hline Redox potential & $\mathrm{mV}$ & $\begin{array}{l}\text { Important for speciation calculations of } \\
\text { mineral phases (and selected MNs) }{ }^{3}\end{array}$ & Standard & 3 & 23,70 \\
\hline Sludge volume index & $\mathrm{mg} \mathrm{g}^{-1}$ & $\begin{array}{l}\text { Informs about the 'quality' of the sewage } \\
\text { sludge }^{1}\end{array}$ & $\begin{array}{l}\text { Assay- } \\
\text { specific }\end{array}$ & 1 & 147 \\
\hline Major cations & $\mathrm{mg} \mathrm{L}^{-1}$ & $\begin{array}{l}\text { Required for the accurate calculation of } \\
\text { the ionic strength (key parameter for } \\
\text { stability calculations) }{ }^{1-3}\end{array}$ & $\begin{array}{l}\text { Assay- } \\
\text { specific }\end{array}$ & $(1,2,3)$ & 20 \\
\hline Major anions & $\mathrm{mg} \mathrm{L}^{-1}$ & $\begin{array}{l}\text { Required for the accurate calculation of } \\
\text { the ionic strength (key parameter for } \\
\text { stability calculations) }{ }^{1-3}\end{array}$ & $\begin{array}{l}\text { Assay- } \\
\text { specific }\end{array}$ & $(1,2,3)$ & 20 \\
\hline TOC & $\mathrm{mg} \mathrm{L}^{-1}$ & $\begin{array}{l}\text { Informs about the state / performance of } \\
\text { the wastewater treatment process }{ }^{1,2} \text {, gives } \\
\text { an indication of the biological activity in } \\
\text { the landfill. }\end{array}$ & $\begin{array}{l}\text { Assay- } \\
\text { specific }\end{array}$ & $(1,2,3)$ & $21,67,68$ \\
\hline $\mathrm{O}_{2}$ & $\mathrm{mg} \mathrm{L}^{-1}$ & $\begin{array}{l}\text { Provides information about the } \\
\text { wastewater treatment process } \\
\text { (nitrification, denitrification) and } \\
\text { characterizes the respective sludge (oxic / }\end{array}$ & $\begin{array}{l}\text { Assay- } \\
\text { specific }\end{array}$ & $(1,3)$ & 148 \\
\hline
\end{tabular}




\begin{tabular}{|c|c|c|c|c|c|}
\hline & & $\begin{array}{l}\text { anoxic) }{ }^{1} \text {, informs about the conditions } \\
\text { and processes in the landfill (influences } \\
\text { mineral / NM stability) }{ }^{3} \text {. }\end{array}$ & & & \\
\hline Nitrate & $\mathrm{mg} \mathrm{L}^{-1}$ & $\begin{array}{l}\text { Key parameter used to evaluate the } \\
\text { performance of the wastewater treatment } \\
\text { process }{ }^{1,2}\end{array}$ & $\begin{array}{l}\text { Assay- } \\
\text { specific }\end{array}$ & $(1,2)$ & 149 \\
\hline Ammonium & $\mathrm{mg} \mathrm{L}^{-1}$ & $\begin{array}{l}\text { Important to assess the performance of the } \\
\text { wastewater treatment process } \\
\text { (nitrification) }{ }^{1}\end{array}$ & $\begin{array}{l}\text { Assay- } \\
\text { specific }\end{array}$ & (1) & 150 \\
\hline
\end{tabular}

${ }^{1}$ : activated sludge ${ }^{2}$ : treated wastewater, ${ }^{3}$ : landfill leachate. Values in bracket refer to secondary measurements for the different media types.

\subsubsection{Considerations of benchmark media for specific parameter values}

Sludge. Depending on the process design of a wastewater treatment plant and on the specific requirements, different types of sludge are used / produced. Examples include primary sludge, activated sludge, granular sludge and digested sludge. A typical sludge, as summarized from various sources ${ }^{151}$ is the primary solid-containing residual produced from the separation of water and solids in the primary, secondary and tertiary wastewater treatment processes. Due to the widespread use of the activated sludge process currently, and due to that fact that entire wastewater (with the exception of the storm water overflow) and thus all the NMs contained therein, passes through the activated sludge stage, we identified the activated sludge as the most relevant sludge type. Activated sludge mainly consists of bacteria and protozoa that form biological flocs. Activated sludge must be biologically active to allow degradation of wastes and could be affected by NMs. The partitioning of NMs to sludge indicates the amounts of NMs that may pass through sewage treatment processes and enter receiving soils, sediments, and surface waters. Sewage sludge is expected to represent a major sink for many NMs ${ }^{152,153}(94,95)$ and waste water treatment plants will therefore be central to decipher the fate of NMs after their use.

A standardized activated sludge is not available. For analytical purposes, a powered sludge is available as standard reference material (e.g. SRM 2781, National Institute of Standards and Technology, Gaithersburg, Maryland, USA), but powdered sludge cannot be used as an analog for activated sludge for the purpose outlined in this paper. Several authors used sewage sludge collected from field- or pilot - scale wastewater treatment plants to study the behavior of NMs in sludge medium. ${ }^{91,92,154}$ We argue that the general properties of sewage sludge resulting from the activated sludge process are broadly comparable. Therefore, we recommend use of activated sludge collected from local sewage treatment plants as sludge media. By reporting the key parameters described above (Table 8), differences in the general properties of the sludge are revealed and can be discussed.

Treated wastewater. Engineered NMs are released into municipal wastewater streams towards the end of the lifetime of the materials, where the NM will partition into the solid phase (sludge, or biosolids) or aqueous phase (effluent). A majority (>95\%) of NMs tend to be attached to the heterogeneous, dense bacterial communities found in biological wastewater treatment processes. ${ }^{155-157}$ Nevertheless, despite the efficient removal of NMs during the wastewater treatment, a small fraction still escapes the treatment and is discharged into the surface waters. Therefore, we consider treated wastewater as an important medium to assess potential exposure routes for NMs. 
A standardized treated wastewater does not exist; however, wastewater effluents need to fulfill certain quality criteria before being discharged into surface waters. Although these criteria can vary from country to country, they set a general baseline for the quality of treated wastewater. In addition to variations caused by different influent waters (industrial versus municipal), the contents of dissolved components are further influenced by the geological environment (e.g. granites, sedimentary rocks or limestone). Thus, the natural variability caused by the geological settings may lead to considerable differences of dissolved components in treated wastewater. We suggest to use the 'Moderately Hard Reconstituted Water (MHRW)' described in the aqueous media section (section 3.1.3), with a few modifications as an analog for treated wastewater. The most important modifiecations recommendations are strongly elevated concentrations of $\mathrm{Na}^{+}$and $\mathrm{Cl}^{-}$, and possibly $\mathrm{HCO}_{3}{ }^{-}$, affecting the ionic strength of the treated wastewater and thereby the colloidal stability of NMs. Furthermore, increased concentrations of DOC in treated wastewater are conceivable, which may stabilize NMs against agglomeration. Thus, we suggest modifying the MHRW by increasing the $\mathrm{Na}^{+}$and $\mathrm{Cl}^{-}$concentrations to $100 \mathrm{mg} \mathrm{L}^{-1}$ each. The DOC can be adjusted to $10 \mathrm{mgL}^{-1}$, representing effluent values of proper operating WWTPs, by adding humic acid, as per Table SI.4.2.

Landfill effluent. Four different types of landfills (sanitary, municipal solid waste (MSW), construction and demolition, and industrial waste landfills) are generally distinguished, each of which receive different kinds of wastes. The most important categories of landfill materials include MSW, which are either directly landfilled or are incinerated and landfilled mainly as bottom ash. In developed counties, incineration of municipal waste is most popular, but the disposal of MSW in landfill remains the most important waste management strategy worldwide. ${ }^{158}$ The properties of the landfill effluents strongly vary with: i) the type of landfill (and thus the kinds of materials that are deposited); ii) the operation principles; and iii) the age of the landfill. ${ }^{159}$ The most important parameters determining the composition of the landfill leachates (MSW) is the age of the landfill which is related to the respective landfill fermentation stage. ${ }^{160}$ The following four phases are typically described: Aerobic, acid, initial methanogenic, stable methanogenic. Over extended periods of time (hundreds to thousands of years), other phases have been postulated, however, the composition of the respective leachates are still very speculative as no experimental data are available for such systems. ${ }^{159}$

We therefore identified the leachate originating from an MSW landfill under the stable methanogenic phase, which lasts longest (of the three phases for which experimental data are available) and extends over several decades, as the most relevant and suitable for harmonization purposes. As no reference or standardized landfill leachate compositions are available, we recommend average values reported in the literature ${ }^{159}$ (and refs therein) to define an average landfill leachate which can be used for NMs testing purposes. $\mathrm{Cl}^{-}$and $\mathrm{Na}^{+}$(both up to 1 to $2 \mathrm{gL}^{-1}$ ) are much higher than in treated wastewater, but considerably lower compared to ASW (see water media) and also $\mathrm{K}^{+}$concentration can reach $1 \mathrm{~g} \mathrm{~L}^{-1}$. Furthermore, Ca and sulfate concentrations can be as high as a few hundred $\mathrm{mg} \mathrm{L}^{-1}$. The considerably increase in ionic strength may strongly affect the agglomeration behavior of ENP in landfill effluents. Furthermore, DOC (extrapolated from $B O D$ and $C O D$ values reported by Kjeldsen ${ }^{159}$ ) can range from a few tens to a few thousands $\mathrm{mgL}^{-1}$. This large variation makes a selection of one specific value rather arbitrary. However, for a worst case scenario, we recommend using elevated DOC concentrations added in the form of humic acid. Following this reasoning, we recommend modifying the MHRW 
medium by adjusting the $\mathrm{Cl}^{-}$and $\mathrm{Na}^{+}$concentrations to $1000 \mathrm{mgL}^{-1}$ and a Ca concentration of $100 \mathrm{mgL}^{-1}$. Furthermore, DOC concentrations of $1000 \mathrm{mgL}^{-1}$ should be adjusted by adding respective amounts of humic acid, as per Table SI.4.3.

\subsubsection{Key challenges and trade-offs guiding parameter and benchmark suggestions}

Activated sludge: Sewage sludge is a biologically active medium and can therefore not be stored over extended periods of time. However, minor differences in activated sludge properties are not expected to have dramatic effects of the behavior of NMs in the activated sludge. Therefore, rather than defining a reference sewage sludge, we recommend that activated sewage sludge from pilot or full-scale treatment plants should be used for experiments. Reporting key parameters of the sludge as recommended in this study will then allow comparing the different sludge qualities used in experimental studies.

Treated wastewater: This medium can be influenced by the geological setting. In a setting typically dominated by sedimentary rocks, $\mathrm{Ca}^{2+}$ concentrations between 50 and $60 \mathrm{mgL}^{-1}$ are reported in surface waters in Switzerland as well as in wastewater effluents. Surface waters (and treated wastewaters) originating from geological settings dominated by plutonic or metamorphic rocks (e.g. granites and gneisses), show considerably lower $\mathrm{Ca}^{2+}$ concentrations on the order of $20 \mathrm{mgL}^{-1}$. Thus, elevated concentrations of $\mathrm{Ca}^{2+}$ caused by the (geological) background may have a more pronounced (and site specific) impact on NM behavior than the increased concentrations of $\mathrm{Na}^{+}$and $\mathrm{Cl}^{-}$, related to the wastewater.

Landfill leachate: Landfill leachates are very variable depending on the type of waste that is deposited. In addition, there is also a temporal component resulting from the degradation of the organic matrix in the waste material, which changes for example $\mathrm{pH}$ and dissolved inorganic components. Furthermore, DOC changes its composition and decreases in quantity by more than an order of magnitude over time. The suggested medium compositions therefore only represent one kind of landfill at a certain time of landfill evolution.

\subsection{Product matrix media}

\subsubsection{Context and background}

Previous sections focused on environmental testing media in which NMs are investigated. There is one critical additional medium that the ENM are in contact with, and this is the product matrix they may be embedded in or deposited on through their use in nano-enabled products. In fact, only in a situation where free NMs are added by release into an environmental medium, are they actually in direct contact with that medium apart from the surrounding product matrix. Because it has been shown that actually released NM are for polymer nanocomposites to a large extent still embedded in or associated with the matrix they were present inside the product, ${ }^{161}$ there is in fact a medium-in-medium situation in all testing media if realistic exposure conditions are targeted. It is important to develop methods and consistent characterization of product matrix media, as part of thorough harmonization across NM lifecycles. A number of projects throughout the EU and US currently focus on NMs within their product lifecycles. ${ }^{162,163}$

\subsubsection{Recommended media and parameters}


The harmonization of the product matrix characterization poses challenges that are different to those encountered for environmental media, due to enormous variability in product types and phases. However, harmonizing reporting of product medium characteristics remains critical for comparability of studies. As a starting point to categorize product matrices, the NM categorization scheme from ${ }^{164}$ can be used. These authors define the materials depending on the location of the nanostructure in the system. For our purposes, their third category "Materials that contain nanostructured particles" is relevant. Its four subcategories are:

- surface bound,

- suspended in liquids,

- suspended in solids,

- free (the scope of this manuscript which excludes consideration of air, "free" includes intentionally directly released nanomaterial products into media other than air).

Figure 2 highlights that under realistic conditions we need to consider the fact that in an environmental testing medium different product matrices should be tested with the free NM being one among four subcategories.

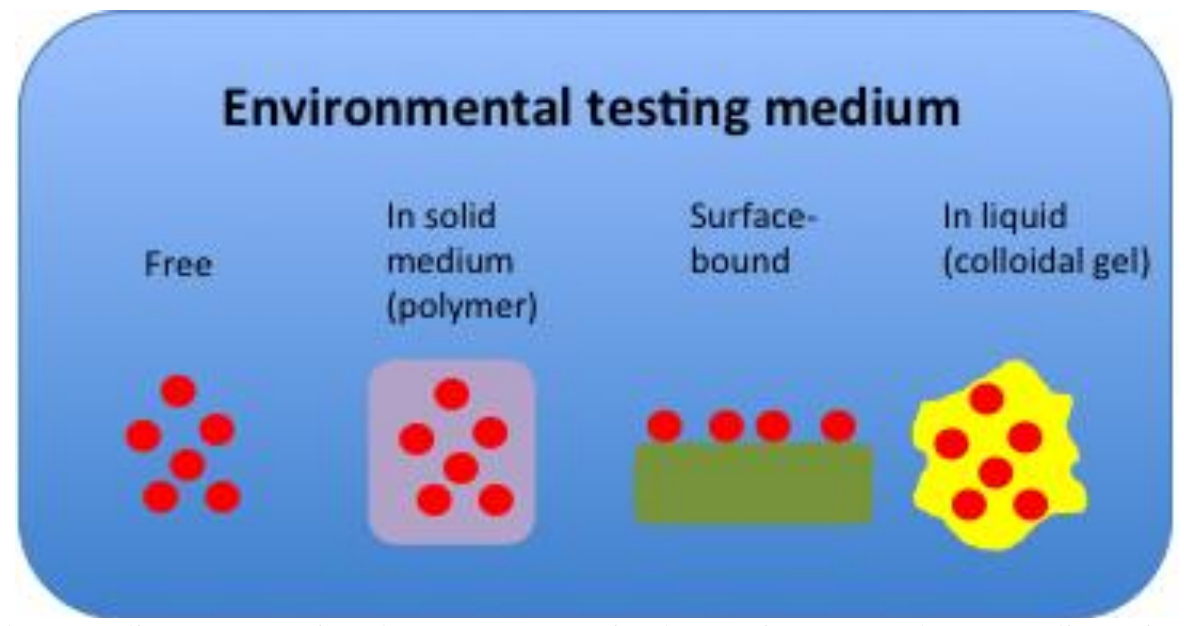

Figure 2: Product medium categories that are present in the environmental test medium: in addition to free NM, NMs contained in solid and liquid media and bound onto surfaces need to be considered based on the framework of ${ }^{164}$.

Whereas the four general categories from Hansen et al. are relatively straightforward to define, the harmonization of product matrix testing media is hampered by the sheer number of possible $\mathrm{NM}$ /product combinations. For each category, a large number of potential matrices with very different chemical-physical behavior could be chosen. For the solid medium for example, the range of matrices could go from polyethylene to concrete and it has been shown that the potential for release of NMs from these matrices varies by five orders of magnitude. ${ }^{165}$ Moreover, for a given matrix, different additives/surface coatings have to be used depending on the NM to be incorporated in order to allow NM dispersion and facilitate NM/Matrix compatibility.

Most published studies on release of NMs from a product matrix have used commercially available products with only limited description of the matrix and only in a few studies has a more defined matrix been used. ${ }^{166}$ To study NM release from paints, standard paint formulations have been described in the NanoHouse project. ${ }^{167,168}$ For polymer nanocomposites, standard 
materials have been used in inter-laboratory comparisons. ${ }^{169}$ Also for NM release from textiles, materials with full characterization of the fabrics and the methods to produce them have been described. ${ }^{170}$ A number of case studies have emerged including methods to generate and characterize releases from matrix-embedded materials. ${ }^{171}$ These few studies with materials that are relatively well described are clearly not sufficient to allow the proposition of standard testing materials for product matrices.

The recommended product matrices are shown in Table 9. Two are solid matrices with NMs embedded in it or with surface-bound NM, one is a colloidal suspension of NMs (e.g. a cream). The primary measurements that are needed are the NM concentration inside the matrix and the composition of the matrix. In the case of nano-enabled products, NM concentrations may be significant due to potential impacts on the matrix structure itself in addition to a direct impact on release rates. ${ }^{172}$ Depending on whether the NM/matrix is obtained from a commercial source or is produced in-house, more or less information is available about the matrix and the embedded NMs. The characterization of the identity of the NM and the chemical composition of the matrix is more challenging in the case of a commercial product and often relies on manufacturer's information only. It is therefore recommended to produce the matrix in-house to allow a full control over its composition and the type of NM added. A very close collaboration with manufacturers and a full disclosure of all ingredients of the matrix is also a preferred option because it ensures that the matrix is relevant from a real-world perspective but still allows full knowledge about the matrix composition. The use of "generic" formulations that combine the requirement of both scientists and industry has been shown to be a good compromise. ${ }^{173}$

A secondary set of measurements should deal with the changes in product matrix over time when added to an environmental medium. The product matrix ages over time when present in an environmental medium and these changes drive the behavior of the NM. The characterization of the "matrix in the matrix", i.e. the product matrix that is present in the environmental matrix, is also necessary.

Table 9: Minimum set of parameters recommended for product matrix media

\begin{tabular}{|l|l|c|}
\hline Media type & Primary Measurements (matrix) & Secondary Measurements (material release) \\
\hline $\begin{array}{l}\text { Solid matrix with } \\
\text { nanomaterials } \\
\text { embedded }\end{array}$ & $\begin{array}{l}\bullet \text { nanomaterial concentration } \\
\bullet\end{array}$ & $\begin{array}{l}0 \text { composition of product matrix } \\
\text { changes in product matrix over time }\end{array}$ \\
\hline $\begin{array}{l}\text { Solid matrix with } \\
\text { surface bound } \\
\text { nanomaterials }\end{array}$ & $\bullet-$ composition of product matrix & $\circ$ changes in product matrix over time \\
\hline $\begin{array}{l}\text { Colloidal } \\
\text { suspension of } \\
\text { nanomaterials }\end{array}$ & $\bullet$ composition of product suspension & 0 \\
\hline
\end{tabular}


The recommendations for harmonizing across this medium are therefore not equivalent to selecting a particular representative matrix in the way that aqueous, soils, biological or even engineered matrices may present. In this case, the recommendations are limited to conditional lists of parameters that are appropriate to report for comparison across the broadly varying set of product matrices into which NMs will be incorporated.

\subsubsection{Considerations of benchmark media for specific parameter values}

Solid matrix with NMs embedded: This type of matrix is one of the most frequently used product matrices ${ }^{165,166}$ and also constitutes the major type of matrix reported in release studies. ${ }^{161}$ Not all $\mathrm{NM}$ /matrix combinations make sense from the point of view of actual product use and therefore for each combination another test material might be needed. The chemical 'compatibility' between matrix and NM must be taken into account. This means that different to the environmental testing media, where all NMs can enter the same system, in the case of the product matrix different test media need to be prepared for each NM and each product type that exists. In that specific case the application domain needs to be taken into account. The matrix composition needs to be known or has to be determined analytically regardless if a commercially available matrix or one produced in-house is used. It has been shown that it is mainly the type of matrix that determined the release of materials. ${ }^{165}$

Solid matrix with surface bound NMs: The general issues discussed for NMs embedded in a solid matrix also apply to surface-bound NMs. This choice of this matrix is justified by the much higher release potential of NMs when bound onto the surface than when incorporated into / embedded in the matrix. ${ }^{174}$ The technology used to bind the NMs onto the surface is a crucial determinant of the system and needs to be known so that the behavior can be linked to composition.

Colloidal suspension of NMs: This matrix represents the simplest form of a product matrix because the NMs are present suspended in a liquid (or gel) matrix, therefore being similar to the pristine NMs that are usually used in experiments. Nevertheless, the additional presence of matrix materials influences the behavior of the NMs in the system and therefore the detailed characterization of the matrix and knowledge about the major constituents is necessary. While there have been a number of studies, there is not convergence on a reference matrix that can span across groupings or even phases. It may be that more specialized groupings can be developed based in part on use and in part on phase (e.g. liquid foods require a particular set of characteristics to harmonize reporting).

\subsubsection{Key challenges and trade-offs guiding parameter and benchmark suggestions}

The choice of the product matrix is determined by the actual application of a specific NM and therefore no distinct recommendations for a small set of matrices can be made. The matrix choice depends on the NM that is investigated and the type of product that is the focus of the study. However, the three general recommendations on product matrices made represent the majority of real-world applications of NMs that are of environmental relevance and thus should be targeted in environmental studies. 


\section{DISCUSSION}

A number of consistently observed tensions were encountered in selecting and compromising on harmonized media, including the desire to propose a minimum set of characteristics that would be required for comparison without overburdening researchers. The separation of recommended measurements into primary and secondary parameters addresses that tension. Another significant difficulty was encountered in separating media conditions from broader assay conditions; the scope of this effort was limited to characterizing the media in which NMs are tested. Integrated data and cross-study comparison will be enabled by a combination of the harmonized media parameters proposed here, together with standard material characterizations and assays. This was especially challenging for the biological fluids, waste water treatment and product categories, where several iterations were required to tease out the boundaries between medium and assay. Figure 3 shows the split that was agreed for the biological fluids parameters as a representative example.

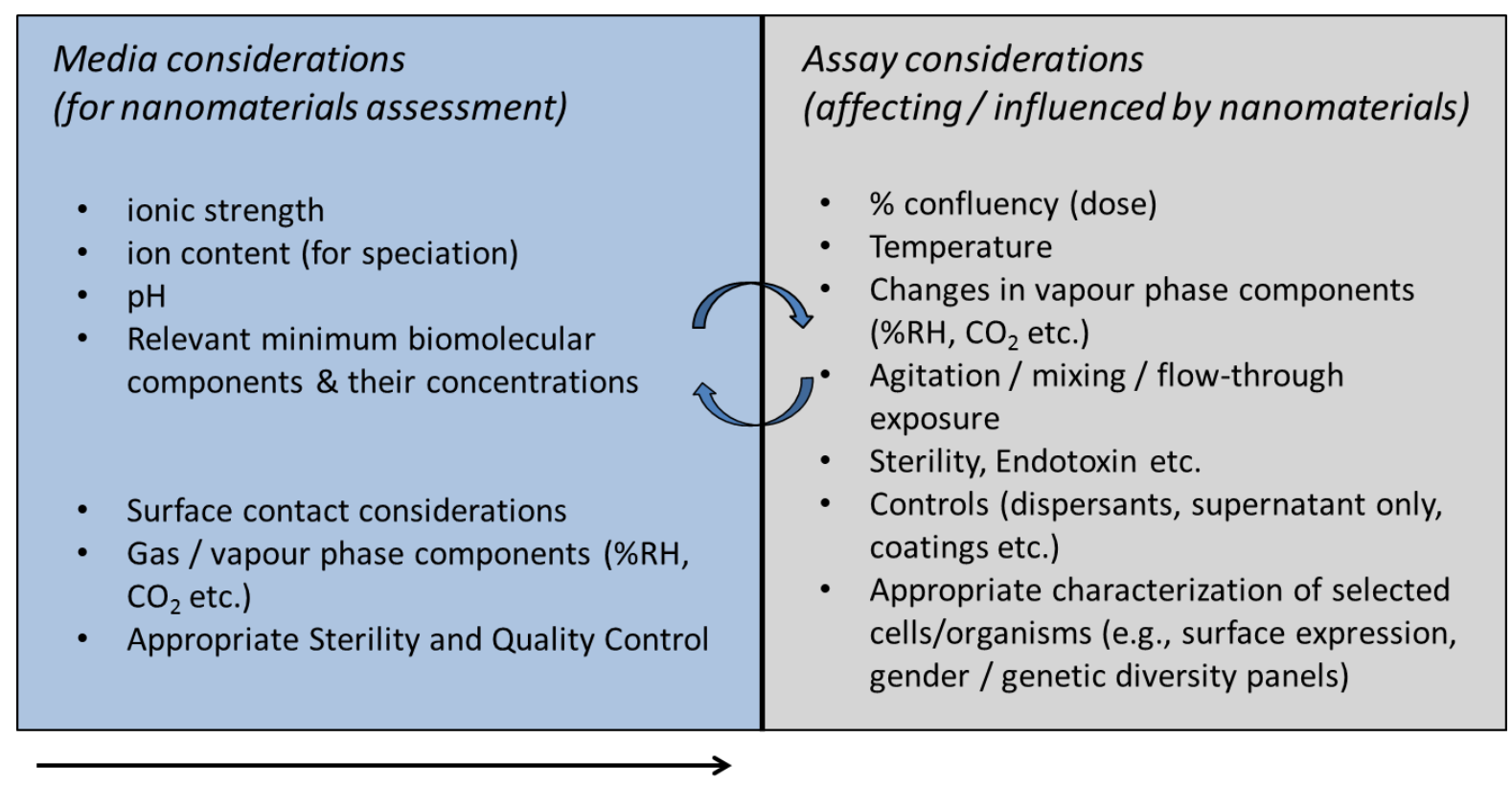

ENTM focus is on media only

Figure 3: Distinction between media considerations, which are the focus of the current paper, and assay conditions, which while important and not the focus of the current paper. Thus, the key parameters discussed in the previous sections focused on the medium conditions only.

No synthetic media will cover full range of natural environmental conditions nor biological conditions, given the natural variation within the systems. Tables 1, 3, 5, 7 and 9 illustrate the main sub-groups identified as being priority media for discussion, and consideration of whether a standard media was currently available, and whether this could be recommended as a harmonized test medium for NMs testing as a means to enhance the comparability of results from different labs and different experiments. The minimum sub-set of media conditions within a category was 3 for the wastewater and product categories, with soil have 5 conditions, water having 4. Biological media spanned a wide range if conditions for cell culture, simulated or 
artificial body fluids mimicking the various routes of exposure (inhalation, via the gut, via dermal contact or direct injection into the bloodstream) as well as less routine points of potential contact such as exposure via the eye.

Selecting reference systems and key parameters can allow for efficient generation of large arrays of standardized and mutually comparable data. Such data may be used in a regulatory context as well as for scientific investigations, and in the future serve as the basis for efficient development of grouping and read across approaches as well as for development of models capable of predicting key fate and effect parameters of NMs. To fulfill these requirements, it is essential that the selected set of parameters allows investigation of possible effects of soil and/or NM properties on different functional assays (as an example: dissolution rate of NMs in soils). Typically, in regulatory frameworks there is the desire to generate data and develop scenarios that are representative of realistic worst-case conditions, whereas such conditions might be of less relevance for non-regulatory purposes.

The next logical steps toward generating useful combined data will include coalescing investigations around common interests that are worth amassing combined, comparable data, including likely exposure scenarios and important transformation processes. Obtaining integrated comparable data will allow us to investigate structure activity relationships, test the efficacy of functional assay measurements as alternative testing approaches to forecast NM behavior in relevant media in a way that inherently captures the kinetics and lack of equilibrium within the combined systems, and support categorization strategies. Moving beyond this, we can aim to support functionality-based categorization strategies for regulatory purposes, since often the same useful properties that are the basis for their efficacy and reason for their use.

\section{CONCLUSIONS:}

We know the media surrounding NMs are key determinants of the transformations those NMs will undergo, and of the ultimate characteristics of the the resulting materials that will be moving through environments and taken up into biota. Because the characteristics and effects of the material are actually a function of the combined system of the material and the media in which it is tested, data characterizing both the material and the media must be reported together to facilitate meaningful analysis. We also know that integrating and comparing multiple datasets is necessary to make progress on understanding behavior and effects of NMs, given the infinite variety of materials and media and the limits of any one individual project. To enable this, we must harmonize data reporting not only on NM characteristics but also of media; and to start toward harmonization, we must select some sample media which are expected to be of particular relevance to guidance and decision making on the part of risk assessors, regulators, and manufacturers. Prior calls have been made for consolidating testing efforts around key functional assays that deliver empirical measurements of how nanomaterials behave in particular systems (e.g. attachment efficiency, dissolution). If such tests are carried out in consistent reference media, the resulting datasets will be comparable, and can propel the nanoEHS community toward both directional guidance for risk purposes, as well as provide a growing mass of meta- 
data to back out the mechanistic interactions between particle and medium property that governed the FA result. ${ }^{6}$

We hope that the proposals in this manuscript of primary and secondary parameters to be consistently reported for several key classes of media will be adopted by the broad array of communities engaged in NM testing. In cases where a standard or synthesized medium is relevant, we hope that the proposed values that are provided in the SI section for a number of suggested standardized media may be of use wherever possible. Researchers will of course use the medium that best allows interrogation of their system for their research question, but where there is flexibility, the standard system offers value in enabling direct comparison to other adoptive experiments and could be tested in addition. This co-analysis potential will be particularly relevant when data are then entered, as is increasingly the goal, into shared databases (NanoInformatics Knowledge Commons, eNanoMapper, the developing NanoCommons and EUON).

For several of the more complex media categories here, there are important next steps to be realized in analysis and detection (e.g. characterization of NMs in situ within product matrices), and in agreement of most relevant systems (e.g. insights from life cycle analysis to align product matrices with environmental compartments of their likely release). As these insights emerge, continued harmonization of environmental media for NM testing will be improved. Work in the US-EU nanoEHS Communities of Research to coordinate and harmonize efforts in multiple projects and regions may serve as a platform for continued development and discussion.

\section{SUPPORTING INFORMATION}

\section{ACKLOWLEDGEMENTS}

N K Geitner and C Ogilvie Hendren contributed equally to the organization and preparation of the manuscript. G Cornelis, R Kaegi, J Lead, G V Lowry, I Lynch, B Nowack, and E Petersen were workshop group leaders and primary contributors to the major sections of the manuscript; they are listed alphabetically after the two lead authors. The remaining authors took part in the workshop and contributed material directly to the final manuscript; they are listed alphabetically after the core contributors. C Ogilvie Hendren lead the design and facilitation of the workshop. M R Wiesner convened the workshop and serves as corresponding author.

This material is based upon work supported by the National Science Foundation (NSF) and the Environmental Protection Agency (EPA) under NSF Cooperative Agreement EF-0830093 and DBI-1266252, Center for the Environmental Implications of NanoTechnology (CEINT). The work was also supported in part via cooperative agreement W912HZ-17-2-0002 between the US Army Corps of Engineer Research and Development Center (USACE ERDC)and the US Consumer Product Safety Commission. Any opinions, findings, conclusions or recommendations 
expressed in this material are those of the author(s) and do not necessarily reflect the views of the NSF, the EPA, the USACE ERDC or the US CPSC. This work has not been subjected to EPA review and no official endorsement should be inferred.

References

1. Stefaniak, A. B.; Hackley, V. A.; Roebben, G.; Ehara, K.; Hankin, S.; Postek, M. T.; Lynch, I.; Fu, W. E.; Linsinger, T. P.; Thunemann, A. F., Nanoscale reference materials for environmental, health and safety measurements: needs, gaps and opportunities. Nanotoxicology 2013, 7, (8), 1325-37.

2. Hendren, C. O.; Powers, C. M.; Hoover, M. D.; Harper, S. L., The Nanomaterial Data Curation Initiative: A collaborative approach to assessing, evaluating, and advancing the state of the field. Beilstein J Nanotechnol 2015, 6, 1752-62.

3. Stone, V.; Nowack, B.; Baun, A.; van den Brink, N.; Kammer, F.; Dusinska, M.; Handy, R.; Hankin, S.; Hassellov, M.; Joner, E.; Fernandes, T. F., Nanomaterials for environmental studies: classification, reference material issues, and strategies for physico-chemical characterisation. Sci Total Environ 2010, 408, (7), 1745-54.

4. Harper, S. L.; Carriere, J. L.; Miller, J. M.; Hutchison, J. E.; Maddux, B. L.; Tanguay, R. L., Systematic evaluation of nanomaterial toxicity: utility of standardized materials and rapid assays. ACS Nano 2011, 5, (6), 4688-97.

5. $\quad$ Karcher, S.; Willighagen, E. L.; Rumble, J.; Ehrhart, F.; Evelo, C. T.; Fritts, M.; Gaheen, S.; Harper, S. L.; Hoover, M. D.; Jeliazkova, N.; Lewinski, N.; Marchese Robinson, R. L.; Mills, K. C.; Mustad, A. P.; Thomas, D. G.; Tsiliki, G.; Ogilvie Hendren, C., Integration among databases and data sets to support productive nanotechnology: Challenges and recommendations.

Nanolmpact 2018, 9, 85-101.

6. Hendren, C. O.; Lowry, G. V.; Unrine, J. M.; Wiesner, M. R., A functional assay-based strategy for nanomaterial risk forecasting. Sci Total Environ 2015, 536, 1029-1037.

7. Vencalek, B. E.; Laughton, S. N.; Spielman-Sun, E.; Rodrigues, S. M.; Unrine, J. M.; Lowry, G. V.; Gregory, K. B., In Situ Measurement of $\mathrm{CuO}$ and $\mathrm{Cu}(\mathrm{OH}) 2$ Nanoparticle Dissolution Rates in Quiescent Freshwater Mesocosms. Environmental Science \& Technology Letters 2016, 3, (10), 375-380.

8. Geitner, N. K.; O'Brien, N. J.; Turner, A. A.; Cummins, E. J.; Wiesner, M. R., Measuring Nanoparticle Attachment Efficiency in Complex Systems. Environ Sci Technol 2017, 51, (22), 13288-13294.

9. Thomas, D. G.; Gaheen, S.; Harper, S. L.; Fritts, M.; Klaessig, F.; Hahn-Dantona, E.; Paik, D.; Pan, S.; Stafford, G. A.; Freund, E. T.; Klemm, J. D.; Baker, N. A., ISA-TAB-Nano: a specification for sharing nanomaterial research data in spreadsheet-based format. $B M C$ Biotechnol 2013, 13, (1), 2.

10. Lowry, G. V.; Hill, R. J.; Harper, S.; Rawle, A. F.; Hendren, C. O.; Klaessig, F.; Nobbmann, U.; Sayre, P.; Rumble, J., Guidance to improve the scientific value of zeta-potential measurements in nanoEHS. Environmental Science: Nano 2016, 3, (5), 953-965. 
11. Wiesner, M. R.; Lowry, G. V.; Jones, K. L.; Hochella, J., Michael F; Di Giulio, R. T.; Casman, E.; Bernhardt, E. S., Decreasing uncertainties in assessing environmental exposure, risk, and ecological implications of nanomaterials. In ACS Publications: 2009.

12. Nowack, B.; Ranville, J. F.; Diamond, S.; Gallego-Urrea, J. A.; Metcalfe, C.; Rose, J.; Horne, N.; Koelmans, A. A.; Klaine, S. J., Potential scenarios for nanomaterial release and subsequent alteration in the environment. Environ Toxicol Chem 2012, 31, (1), 50-9.

13. Lowry, G. V.; Gregory, K. B.; Apte, S. C.; Lead, J. R., Transformations of nanomaterials in the environment. Environ Sci Technol 2012, 46, (13), 6893-9.

14. Metreveli, G.; Frombold, B.; Seitz, F.; Grun, A.; Philippe, A.; Rosenfeldt, R. R.; Bundschuh, M.; Schulz, R.; Manz, W.; Schaumann, G. E., Impact of chemical composition of ecotoxicological test media on the stability and aggregation status of silver nanoparticles. Environmental Science-Nano 2016, 3, (2), 418-433.

15. Dale, A. L.; Casman, E. A.; Lowry, G. V.; Lead, J. R.; Viparelli, E.; Baalousha, M., Modeling nanomaterial environmental fate in aquatic systems. In ACS Publications: 2015.

16. Weishaar, J. L.; Aiken, G. R.; Bergamaschi, B. A.; Fram, M. S.; Fujii, R.; Mopper, K., Evaluation of specific ultraviolet absorbance as an indicator of the chemical composition and reactivity of dissolved organic carbon. Environmental Science \& Technology 2003, 37, (20), 4702-4708.

17. USEPA, EPA-RCA: 9040B: pH in Water by Electrometric Measurement. In Waste, O. o. S., Ed. SW-846 Online: Test Methods, 1995.

18. International, A., ASTM D1293-18, Standard Test Methods for $\mathrm{pH}$ of Water. In ASTM International: West Conshohocken, PA, 2018.

19. Method 2510: Conductivity. In Standard Methods For the Examination of Water and Wastewater, 2017.

20. Pfaff, J. D.; Hautman, D. P., EPA Method 300.1: Determination of Inorganic Anions in Drinking Water by lon Chromatography. In Laboratory, N. E. R., Ed. 1999.

21. Potter, B. B.; Wimsatt, J. C., Method 415.3 - Measurement of Total Organic Carbon, Dissolved Organic Carbon and Specific UV Absorbance at $254 \mathrm{~nm}$ in Source Water and Drinking Water. In Development, O. o. R. a., Ed. Science Inventory, 2005.

22. W, O. D. J., EPA Method 375.2: Determination of Sulfate by Automated Colorimetry. In Division, C. R., Ed. 1993.

23. Striggow, B., SESDPROC-113-R2: Field Measurement of Oxidation-Reduction Potential. In Division, S. a. E. S., Ed. 2017.

24. W, O. D. J., EPA Method 180.1: Determination of Turbidity by Nephelometry. In Division, C. R., Ed. 1993.

25. International, A., ASTM D5907-18: Standard Test Methods for Filterable Matter (Total Dissolved Solids) and Nonfilterable Matter (Total Suspended Solids) in Water. In ASTM International: West Conshohocken, PA, 2018; Vol. ASTM D5907-18.

26. Petersen, E. J.; Diamond, S. A.; Kennedy, A. J.; Goss, G. G.; Ho, K.; Lead, J.; Hanna, S. K.; Hartmann, N. B.; Hund-Rinke, K.; Mader, B.; Manier, N.; Pandard, P.; Salinas, E. R.; Sayre, P., Adapting OECD Aquatic Toxicity Tests for Use with Manufactured Nanomaterials: Key Issues and Consensus Recommendations. Environ Sci Technol 2015, 49, (16), 9532-47. 
27. Harmon, A. R.; Kennedy, A. J.; Poda, A. R.; Bednar, A. J.; Chappell, M. A.; Steevens, J. A., Determination of nanosilver dissolution kinetics and toxicity in an environmentally relevant aqueous medium. Environ Toxicol Chem 2014, 33, (8), 1783-91.

28. Fabrega, J.; Fawcett, S. R.; Renshaw, J. C.; Lead, J. R., Silver nanoparticle impact on bacterial growth: effect of $\mathrm{pH}$, concentration, and organic matter. Environ Sci Technol 2009, 43, (19), 7285-90.

29. Potasznik, A.; Szymczyk, S., Magnesium and Calcium Concentrations in the Surface Water and Bottom Deposits of a River-Lake System. Journal of Elementology 2015, 20, (3), 677692.

30. Brant, J.; Lecoanet, H.; Wiesner, M. R., Aggregation and deposition characteristics of fullerene nanoparticles in aqueous systems. Journal of Nanoparticle Research 2005, 7, (4-5), 545-553.

31. Su, Y.; Yang, G.; Lu, K.; Petersen, E. J.; Mao, L., Colloidal properties and stability of aqueous suspensions of few-layer graphene: Importance of graphene concentration. Environmental pollution (Barking, Essex : 1987) 2017, 220, (Pt A), 469-477.

32. Coleman, J. G.; Kennedy, A. J.; Bednar, A. J.; Ranville, J. F.; Laird, J. G.; Harmon, A. R.; Hayes, C. A.; Gray, E. P.; Higgins, C. P.; Lotufo, G.; Steevens, J. A., Comparing the effects of nanosilver size and coating variations on bioavailability, internalization, and elimination, using Lumbriculus variegatus. Environ Toxicol Chem 2013, 32, (9), 2069-77.

33. Kennedy, A. J.; Chappell, M. A.; Bednar, A. J.; Ryan, A. C.; Laird, J. G.; Stanley, J. K.; Steevens, J. A., Impact of organic carbon on the stability and toxicity of fresh and stored silver nanoparticles. Environ Sci Technol 2012, 46, (19), 10772-80.

34. Romer, I.; White, T. A.; Baalousha, M.; Chipman, K.; Viant, M. R.; Lead, J. R., Aggregation and dispersion of silver nanoparticles in exposure media for aquatic toxicity tests. $J$ Chromatogr A 2011, 1218, (27), 4226-33.

35. Ma, R.; Levard, C.; Marinakos, S. M.; Cheng, Y.; Liu, J.; Michel, F. M.; Brown, G. E.; Lowry, G. V., Size-controlled dissolution of organic-coated silver nanoparticles. Environ Sci Technol 2012, 46, (2), 752-9.

36. Tejamaya, M.; Romer, I.; Merrifield, R. C.; Lead, J. R., Stability of citrate, PVP, and PEG coated silver nanoparticles in ecotoxicology media. Environ Sci Technol 2012, 46, (13), 7011-7.

37. Hitchman, A.; Smith, G. H.; Ju-Nam, Y.; Sterling, M.; Lead, J. R., The effect of environmentally relevant conditions on PVP stabilised gold nanoparticles. Chemosphere 2013, 90, (2), 410-6.

38. Agency, U. S. E. P., Watershed-based National Pollutant Discharge Elimination System (NPDES) Permitting Technical Guidance. In USEPA: 2007.

39. Agency, U. S. E. P. Analytical Methods and Precedures for Pesticides. https://www.epa.gov/pesticide-analytical-methods

40. Weber, C., Methods for Measuring the Acute Toxicity of Effluents and Receiving Waters to Freshwater and Marine Organisms. In Agency, U. S. E. P., Ed. Washington, D.C.

41. Agency, U. S. E. P. Short-term Methods for Estimating the Chronic Toxicity of Effluents and Receiving Waters to Freshwater Organisms, Fourth Edition; Washington, D.C., 2002.

42. Kennedy, A. J.; Hull, M. S.; Diamond, S.; Chappell, M.; Bednar, A. J.; Laird, J. G.; Melby, N. L.; Steeyens, J. A., Gaining a Critical Mass: A Dose Metric Conversion Case Study Using Silver Nanoparticles. Environmental Science \& Technology 2015, 49, (20), 12490-12499. 
43. Fairbairn, E. A.; Keller, A. A.; Madler, L.; Zhou, D.; Pokhrel, S.; Cherr, G. N., Metal oxide nanomaterials in seawater: linking physicochemical characteristics with biological response in sea urchin development. J Hazard Mater 2011, 192, (3), 1565-71.

44. Johnson, B. D.; Gilbert, S. L.; Khan, B.; Carroll, D. L.; Ringwood, A. H., Cellular responses of eastern oysters, Crassostrea virginica, to titanium dioxide nanoparticles. Mar Environ Res 2015, 111, 135-43.

45. Auffan, M.; Matson, C. W.; Rose, J.; Arnold, M.; Proux, O.; Fayard, B.; Liu, W.; Chaurand, P.; Wiesner, M. R.; Bottero, J. Y.; Di Giulio, R. T., Salinity-dependent silver nanoparticle uptake and transformation by Atlantic killifish (Fundulus heteroclitus) embryos. Nanotoxicology 2014, 8 Suppl 1, (sup1), 167-76.

46. Atkinson, M.; Bingman, C., Elemental composition of commercial seasalts. Journal of Aquariculture and Aquatic Sciences 1997, 8, (2), 39-43.

47. ASTM, Standard Practice for the Preparation of Substitute Ocean Water. In ASTM: 2013.

48. Cavanaugh, G. M., Formulae and methods VI of the Marine Biological Laboratory

Chemical Room. In Cavanaugh, G. M., Ed. Woods Hole, Mass., 1975.

49. Compendia, B. B. Artificial Seawaters - Recipes.

http://comm.archive.mbl.edu/BiologicalBulletin/COMPENDIUM/CompTab3.html\#3A (February 5, 2019),

50. Rodrigues, A.; Brito, A.; Janknecht, P.; Proenca, M. F.; Nogueira, R., Quantification of humic acids in surface water: effects of divalent cations, $\mathrm{pH}$, and filtration. $J$ Environ Monit 2009, 11, (2), 377-82.

51. Volk, C.; Wood, L.; Johnson, B.; Robinson, J.; Zhu, H. W.; Kaplan, L., Monitoring dissolved organic carbon in surface and drinking waters. Journal of Environmental Monitoring 2002, 4, (1), 43-47.

52. Kozin, P.; von der Kammer, F. Clarification of methodical questions regarding the investigation of nanomaterials in the environment Development of a decision support tool for the investigation of nanomaterial's environmental behaviour based on dispersion behaviour and dissolution in relation to various environmental parameters Short report; Vienna, Austria, 2007. 53. Sobek, S.; Tranvik, L. J.; Prairie, Y. T.; Kortelainen, P.; Cole, J. J., Patterns and regulation of dissolved organic carbon: An analysis of 7,500 widely distributed lakes. Limnology and Oceanography 2007, 52, (3), 1208-1219.

54. Buffle, J.; Wilkinson, K. J.; Stoll, S.; Filella, M.; Zhang, J. W., A generalized description of aquatic colloidal interactions: The three-colloidal component approach. Environmental Science \& Technology 1998, 32, (19), 2887-2899.

55. Quik, J. T.; Stuart, M. C.; Wouterse, M.; Peijnenburg, W.; Hendriks, A. J.; van de Meent, D., Natural colloids are the dominant factor in the sedimentation of nanoparticles. Environ Toxicol Chem 2012, 31, (5), 1019-22.

56. Rosta, L.; Vongunten, H. R., Light-Scattering Characterization of Laponite Sols. Journal of Colloid and Interface Science 1990, 134, (2), 397-406.

57. Kim, H. J.; Phenrat, T.; Tilton, R. D.; Lowry, G. V., Effect of kaolinite, silica fines and pH on transport of polymer-modified zero valent iron nano-particles in heterogeneous porous media. J Colloid Interface Sci 2012, 370, (1), 1-10. 
58. Wang, D.; Bradford, S. A.; Harvey, R. W.; Gao, B.; Cang, L.; Zhou, D., Humic acid facilitates the transport of ARS-labeled hydroxyapatite nanoparticles in iron oxyhydroxidecoated sand. Environ Sci Technol 2012, 46, (5), 2738-45.

59. Baalousha, M.; Kammer, F. V. D.; Motelica-Heino, M.; Baborowski, M.; Hofmeister, C.; Le Coustumer, P., Size-based speciation of natural colloidal particles by flow field flow fractionation, inductively coupled plasma-mass spectroscopy, and transmission electron microscopy/X-ray energy dispersive spectroscopy: Colloids-trace element interaction. Environmental Science \& Technology 2006, 40, (7), 2156-2162.

60. Hassellov, M.; von der Kammer, F., Iron Oxides as Geochemical Nanovectors for Metal Transport in Soil-River Systems. Elements 2008, 4, (6), 401-406.

61. Cornelis, G.; Hund-Rinke, K.; Kuhlbusch, T.; Van den Brink, N.; Nickel, C., Fate and Bioavailability of Engineered Nanoparticles in Soils: A Review. Critical Reviews in Environmental Science and Technology 2014, 44, (24), 2720-2764.

62. Hotze, E. M.; Phenrat, T.; Lowry, G. V., Nanoparticle aggregation: challenges to understanding transport and reactivity in the environment. J Environ Qual 2010, 39, (6), 190924.

63. Ferry, J. L.; Craig, P.; Hexel, C.; Sisco, P.; Frey, R.; Pennington, P. L.; Fulton, M. H.; Scott, I. G.; Decho, A. W.; Kashiwada, S.; Murphy, C. J.; Shaw, T. J., Transfer of gold nanoparticles from the water column to the estuarine food web. Nat Nanotechnol 2009, 4, (7), 441-4.

64. Petosa, A. R.; Rajput, F.; Selvam, O.; Ohl, C.; Tufenkji, N., Assessing the transport potential of polymeric nanocapsules developed for crop protection. Water Res 2017, 111, 1017.

65. Kookana, R. S.; Boxall, A. B.; Reeves, P. T.; Ashauer, R.; Beulke, S.; Chaudhry, Q.; Cornelis, G.; Fernandes, T. F.; Gan, J.; Kah, M.; Lynch, I.; Ranville, J.; Sinclair, C.; Spurgeon, D.; Tiede, K.; Van den Brink, P. J., Nanopesticides: guiding principles for regulatory evaluation of environmental risks. J Agric Food Chem 2014, 62, (19), 4227-40.

66. EPA, U., Method 9045D: Soil and Waste pH. In Soil and Waste $\mathrm{pH}, \mathrm{U}$ S Environmental Protection Acency: epa.gov, 2004; Vol. 9045D, pp 1-5.

67. International, A., Standard Test Methods for Moisture, Ash, and Organic Matter of Peat and Other Organic Soils. In ASTM INTERNATIONAL: West Conshockocken, PA, 2014; Vol. D297414.

68. Schulte, E. E.; Hoskins, B., Recommended Soil Organic Matter Tests. In Recommended Soil Testing Procedures for the Northeastern United States, Sims, J. T.; Wolf, A., Eds. Agricultural Experiment Station, University of Deleware: Newark, DE, 2011; Vol. 3, pp 63-74.

69. Bowman, G. M.; Hutka, J., Particle Size Analysis. In Soil Physical Measurement and Interpretation for Land Evaluation, McKenzie, N.; Coughlan, K.; Cresswell, H., Eds. CSIRO: Victoria, 2002; pp 224-239.

70. International, A. ASTM Method G200-09 Standard Test Method for Measurement of Oxidation-Reduction Potential (ORP) of Soil. https://www.astm.org/Standards/G200.htm 71. Wolf, A.; Beegle, D., Recommended Soil Tests for Macro and Micronutrients. In Recommended Soil Testing Procedures for the Northeastern United States, Sims, J. T.; Wolf, A., Eds. Agricultural Experiment Station, University of Deleware: Newark, DE, 2011; Vol. 3, pp 3947. 
72. Chapman, P. M.; Wang, F.; Germano, J. D.; Batley, G., Pore water testing and analysis: the good, the bad, and the ugly. Mar Pollut Bull 2002, 44, (5), 359-66.

73. International, A., ASTM D4972-18. Standard Test Methods for pH of Soils. In ASTM International: West Conshohocken, PA, 2018.

74. EPA, U., EPA Method 120.1 - Conductivity. In Development, O. o. R. a., Ed. 1983.

75. Methods of Soil Analysis. Part 2. Chemical and Microbiological Properties. American Society of Agronomy, Soil Science Society of America: Madison, WI, 1965.

76. E, A. H.; W, B.; M, D. D.; D, M. J., EPA Method 376.3 - Analytical Method For

Determination of Acid Volatile Sulfide in Sediment. In Technology, O. o. S. a., Ed. 1991.

77. International, A., ASTM D7063 / D7063M-18, Standard Test Method for Effective

Porosity and Effective Air Voids of Compacted Asphalt Mixture Samples. In ASTM International: West Conshohocken, PA, 2018; Vol. ASTM D7063 / D7063M-18.

78. International, A., ASTM D4647 / D4647M-13, Standard Test Methods for Identification and Classification of Dispersive Clay Soils by the Pinhole Test. In ASTM International: West Conshohocken, PA, 2013; Vol. ASTM D4647 / D4647M-13.

79. International, A., Standard Practice for Active Soil Gas Sampling in the Vadose Zone for Vapor Intrusion Evaluations. In ASTM International: West Conshohocken, PA, 2018; Vol. D766312.

80. BRAGASSA, J. L., Method 3.1 Determining Tortuosity. In IR/IR, Ed. Administrative Record and Information Repository, 2008.

81. OECD, Test No. 207: Earthworm, Acute Toxicity Tests. 1984.

82. Speyer, L. Standard Soils. http://www.lufa-

speyer.de/index.php/dienstleistungen/standardboeden/8-dienstleistungen/artikel/57-

standard-soils

83. Tourinho, P. S.; van Gestel, C. A.; Lofts, S.; Soares, A. M.; Loureiro, S., Influence of soil pH on the toxicity of zinc oxide nanoparticles to the terrestrial isopod Porcellionides pruinosus. Environ Toxicol Chem 2013, 32, (12), 2808-15.

84. Waalewijn-Kool, P. L.; Rupp, S.; Lofts, S.; Svendsen, C.; van Gestel, C. A., Effect of soil organic matter content and $\mathrm{pH}$ on the toxicity of $\mathrm{ZnO}$ nanoparticles to Folsomia candida. Ecotoxicol Environ Saf 2014, 108, 9-15.

85. Ankley, G. T.; Benoit, D. A.; Hoke, R. A.; Leonard, E. N.; West, C. W.; Phipps, G. L.; Mattson, V. R.; Anderson, L. A., Development and Evaluation of Test Methods for Benthic Invertebrates and Sediments - Effects of Flow-Rate and Feeding on Water-Quality and Exposure Conditions. Archives of Environmental Contamination and Toxicology 1993, 25, (1), 12-19.

86. Besser, J. M.; Brumbaugh, W. G.; Kemble, N. E.; Ivey, C. D.; Kunz, J. L.; Ingersoll, C. G.; Rudel, D., Toxicity of nickel-spiked freshwater sediments to benthic invertebrates-Spiking methodology, species sensitivity, and nickel bioavailability. US Geological Survey 2011.

87. Ingersoll, C. G.; Kunz, J. L.; Hughes, J. P.; Wang, N.; Ireland, D. S.; Mount, D. R.; Hockett, J. R.; Valenti, T. W., Jr., Relative sensitivity of an amphipod Hyalella azteca, a midge Chironomus dilutus, and a unionid mussel Lampsilis siliquoidea to a toxic sediment. Environ Toxicol Chem 2015, 34, (5), 1134-44.

88. Call, D. J.; Polkinghorne, C. N.; Markee, T. P.; Brooke, L. T.; Geiger, D. L.; Gorsuch, J. W.; Robillard, K. A., Toxicity of silver in water and sediment to the freshwater amphipod Hyalella azteca. Environ Toxicol Chem 2006, 25, (7), 1802-8. 
89. NIST SRM Order Request System 1646a - Estuarine Sediment. https://wwws.nist.gov/srmors/view detail.cfm?srm=1646a

90. NIST SRM Order Request System RM 8704 - Buffalo River Sediment. https://wwwS.nist.gov/srmors/view detail.cfm?srm $=8704$

91. Ma, R.; Levard, C.; Judy, J. D.; Unrine, J. M.; Durenkamp, M.; Martin, B.; Jefferson, B.; Lowry, G. V., Fate of zinc oxide and silver nanoparticles in a pilot wastewater treatment plant and in processed biosolids. Environ Sci Technol 2014, 48, (1), 104-12.

92. Kaegi, R.; Voegelin, A.; Sinnet, B.; Zuleeg, S.; Hagendorfer, H.; Burkhardt, M.; Siegrist, H., Behavior of metallic silver nanoparticles in a pilot wastewater treatment plant. Environ Sci Technol 2011, 45, (9), 3902-8.

93. Kadish, V. H., Milorganite-A New Fertilizer Material1. Industrial \& Engineering Chemistry 1928, 20, (1), 9-10.

94. Chaney, R. L.; Stoewsand, G. S.; Bache, C. A.; Lisk, D. J., Cadmium deposition and hepatic microsomal induction in mice fed lettuce grown on municipal sludge-amended soil. $J$ Agric Food Chem 1978, 26, (4), 992-4.

95. Anderson, M.; Skerratt, R. G., Variability study of incinerated sewage sludge ash in relation to future use in ceramic brick manufacture. British Ceramic Transactions 2003, 102, (3), 109-113.

96. McNab, N. J.; Hughes, J. C.; Howard, J. R., Pollution effects of wastewater sludge application to sandy soils with particular reference to the behaviour of mercury. Applied Geochemistry 1997, 12, (3), 321-325.

97. Young, S. D.; Zhang, H.; Tye, A. M.; Maxted, A.; Thums, C.; Thornton, I., Characterizing the availability of metals in contaminated soils. I. The solid phase: sequential extraction and isotopic dilution. Soil Use and Management 2005, 21, (s2), 450-458.

98. Dudare, D.; Klavins, M., Peat Humic Substances as Sorbent for Nanomaterials. Geoconference on Nano, Bio and Green - Technologies for a Sustainable Future 2013, 67-74.

99. Hund-Rinke, K.; Baun, A.; Cupi, D.; Fernandes, T. F.; Handy, R.; Kinross, J. H.; Navas, J. M.; Peijnenburg, W.; Schlich, K.; Shaw, B. J.; Scott-Fordsmand, J. J., Regulatory ecotoxicity testing of nanomaterials - proposed modifications of OECD test guidelines based on laboratory experience with silver and titanium dioxide nanoparticles. Nanotoxicology 2016, 10, (10), $1442-$ 1447.

100. Cornelis, G., Fate descriptors for engineered nanoparticles: the good, the bad, and the ugly. Environmental Science-Nano 2015, 2, (1), 19-26.

101. Vasickova, J.; Vana, M.; Komprdova, K.; Hofman, J., The variability of standard artificial soils: effects on the survival and reproduction of springtail (Folsomia candida) and potworm (Enchytraeus crypticus). Ecotoxicol Environ Saf 2015, 114, 38-43.

102. Lesniak, A.; Fenaroli, F.; Monopoli, M. P.; Aberg, C.; Dawson, K. A.; Salvati, A., Effects of the presence or absence of a protein corona on silica nanoparticle uptake and impact on cells. ACS Nano 2012, 6, (7), 5845-57.

103. Albanese, A.; Walkey, C. D.; Olsen, J. B.; Guo, H.; Emili, A.; Chan, W. C., Secreted biomolecules alter the biological identity and cellular interactions of nanoparticles. ACS Nano 2014, 8, (6), 5515-26.

104. Nasser, F.; Lynch, I., Secreted protein eco-corona mediates uptake and impacts of polystyrene nanoparticles on Daphnia magna. J Proteomics 2016, 137, 45-51. 
105. Kreyling, W. G.; Fertsch-Gapp, S.; Schaffler, M.; Johnston, B. D.; Haberl, N.; Pfeiffer, C.; Diendorf, J.; Schleh, C.; Hirn, S.; Semmler-Behnke, M.; Epple, M.; Parak, W. J., In vitro and in vivo interactions of selected nanoparticles with rodent serum proteins and their consequences in biokinetics. Beilstein J Nanotechnol 2014, 5, 1699-711.

106. Hadjidemetriou, M.; Al-Ahmady, Z.; Mazza, M.; Collins, R. F.; Dawson, K.; Kostarelos, K., In Vivo Biomolecule Corona around Blood-Circulating, Clinically Used and Antibody-Targeted Lipid Bilayer Nanoscale Vesicles. ACS Nano 2015, 9, (8), 8142-56.

107. Whitwell, H.; Mackay, R. M.; Elgy, C.; Morgan, C.; Griffiths, M.; Clark, H.; Skipp, P.; Madsen, J., Nanoparticles in the lung and their protein corona: the few proteins that count. Nanotoxicology 2016, 10, (9), 1385-94.

108. Schleh, C.; Kreyling, W. G.; Lehr, C. M., Pulmonary surfactant is indispensable in order to simulate the in vivo situation. Part Fibre Toxicol 2013, 10, (1), 6.

109. Bergin, I. L.; Witzmann, F. A., Nanoparticle toxicity by the gastrointestinal route: evidence and knowledge gaps. Int J Biomed Nanosci Nanotechnol 2013, 3, (1-2), 10.1504/IJBNN.2013.054515.

110. Del Pino, P.; Pelaz, B.; Zhang, Q.; Maffre, P.; Nienhaus, G. U.; Parak, W. J., Protein corona formation around nanoparticles-from the past to the future. Materials Horizons 2014, 1, (3), 301-313.

111. Scientific, T. F. pH and $\mathrm{CO} 2$ Levels. https://www.thermofisher.com/us/en/home/references/gibco-cell-culture-basics/cell-cultureenvironment/ph-co2-levels.html (February 12, 2019),

112. El-Deeb Ghazy, M. M., Habashy, M.M., Mohammady, E.Y. , Effects of pH on Survival, Growth and Reproduction Rates of The Crustacean, Daphnia Magna. Australian Journal of Basic and Applied Sciences, 2011, 5, 1-10.

113. Good, N. E.; Izawa, S., Hydrogen ion buffers. In Methods in enzymology, Elsevier: 1972; Vol. 24, pp 53-68.

114. Monopoli, M. P.; Walczyk, D.; Campbell, A.; Elia, G.; Lynch, I.; Bombelli, F. B.; Dawson, K. A., Physical-chemical aspects of protein corona: relevance to in vitro and in vivo biological impacts of nanoparticles. J Am Chem Soc 2011, 133, (8), 2525-34.

115. Kim, J. A.; Salvati, A.; Aberg, C.; Dawson, K. A., Suppression of nanoparticle cytotoxicity approaching in vivo serum concentrations: limitations of in vitro testing for nanosafety. Nanoscale 2014, 6, (23), 14180-4.

116. Schottler, S.; Klein, K.; Landfester, K.; Mailander, V., Protein source and choice of anticoagulant decisively affect nanoparticle protein corona and cellular uptake. Nanoscale 2016, 8, (10), 5526-36.

117. Lesniak, A.; Campbell, A.; Monopoli, M. P.; Lynch, I.; Salvati, A.; Dawson, K. A., Serum heat inactivation affects protein corona composition and nanoparticle uptake. Biomaterials 2010, 31, (36), 9511-8.

118. Esser, P.; Weitzmann, L., Evaporation from cell culture plates. In Scientific, T., Ed. 2011;

Vol. TILSPNUNCBU02 0111.

119. International, A., ASTM D 513-88: Standard Test Methods for Total and Dissolved Carbon Dioxide in Water. In ASTM International: Philadelphia, PA, 1992; Vol. ASTM D 513-88.

120. Repetitive flaws. Nature 2016, 529, (7586), 256. 
121. Pisani, C.; Rascol, E.; Dorandeu, C.; Gaillard, J. C.; Charnay, C.; Guari, Y.; Chopineau, J.; Armengaud, J.; Devoisselle, J. M.; Prat, O., The species origin of the serum in the culture medium influences the in vitro toxicity of silica nanoparticles to HepG2 cells. PLoS One 2017, 12, (8), e0182906.

122. Duffo, G. S.; Castillo, E. Q., Development of an artificial saliva solution for studying the corrosion behavior of dental alloys. Corrosion 2004, 60, (6), 594-602.

123. Gal, J. Y.; Fovet, Y.; Adib-Yadzi, M., About a synthetic saliva for in vitro studies. Talanta 2001, 53, (6), 1103-1115.

124. Marques, M. R. C., Loebenberg, R., Almukainzi, M., Simulated biological fluids with possible application in dissolution testing. Dissolution Technol 2011, 18, 15-28.

125. Marques, M. R. C.; Loebenberg, R.; Almukainzi, M., Simulated Biological Fluids with Possible Application in Dissolution Testing. Dissolution Technologies 2011, 18, (3), 15-28.

126. Sun, H.; Ruan, Y.; Zhu, H.; Zhang, Z.; Zhang, Y.; Yu, L., Enhanced bioaccumulation of pentachlorophenol in carp in the presence of multi-walled carbon nanotubes. Environ Sci Pollut Res Int 2014, 21, (4), 2865-75.

127. Tao, S.; Lu, Y.; Zhang, D. Y.; Yang, Y. F.; Yang, Y.; Lu, X. X.; Sai, D. J., Assessment of Oral Bioaccessibility of Organochlorine Pesticides in Soil Using an In Vitro Gastrointestinal Model. Environmental Science \& Technology 2009, 43, (12), 4524-4529.

128. Wang, Z. Y., Zhao, J., Song, L., Mashayekhi, H., Chefetz, B., Xing, B.S. , Adsorption and desorption of phenanthrene on carbon nanotubes in simulated gastrointestinal fluids. Environ Sci Technol 2011, 45, 6018-6024.

129. L. S. Smith, h. w. f. o. d. x. e. x. e. h. d. i. t. s., Chapter 1. Digestion in Teleost Fishes In FAO/UNDP Aquaculture Development and Coordination Programme (ADCP) organized a specialized Training Course in Fish Feed Technology at the College of Fisheries, .

130. Wilson, G. R.; Benoit, T. G., Alkaline Ph Activates Bacillus-Thuringiensis Spores. Journal of Invertebrate Pathology 1993, 62, (1), 87-89.

131. Mirshafiee, V.; Kim, R.; Mahmoudi, M.; Kraft, M. L., The importance of selecting a proper biological milieu for protein corona analysis in vitro: Human plasma versus human serum. Int $\mathrm{J}$ Biochem Cell Biol 2016, 75, 188-95.

132. Issaq, H. J.; Xiao, Z.; Veenstra, T. D., Serum and plasma proteomics. Chem Rev 2007, 107, (8), 3601-20.

133. Boisa, N.; Elom, N.; Dean, J. R.; Deary, M. E.; Bird, G.; Entwistle, J. A., Development and application of an inhalation bioaccessibility method (IBM) for lead in the PM10 size fraction of soil. Environment International 2014, 70, 132-142.

134. Cedervall, T.; Lynch, I.; Lindman, S.; Berggard, T.; Thulin, E.; Nilsson, H.; Dawson, K. A.; Linse, S., Understanding the nanoparticle-protein corona using methods to quantify exchange rates and affinities of proteins for nanoparticles. Proceedings of the National Academy of Sciences of the United States of America 2007, 104, (7), 2050-2055.

135. Radic, S.; Geitner, N. K.; Podila, R.; Kakinen, A.; Chen, P.; Ke, P. C.; Ding, F., Competitive binding of natural amphiphiles with graphene derivatives. Sci Rep 2013, 3, 2273.

136. Stark, R. E.; Tian, S., The Cutin Biopolymer Matrix. In Biology of the Plant Cuticle, 2006; pp 126-144.

137. OECD, Nanomaterials in Waste Streams: Current Knowledge on Risks and Impacts. OECD Publishing: 2016. 
138. Werther, J.; Ogada, T., Sewage sludge combustion. Progress in Energy and Combustion Science 1999, 25, (1), 55-116.

139. Sotiriou, G. A.; Singh, D.; Zhang, F.; Chalbot, M. G.; Spielman-Sun, E.; Hoering, L.; Kavouras, I. G.; Lowry, G. V.; Wohlleben, W.; Demokritou, P., Thermal decomposition of nanoenabled thermoplastics: Possible environmental health and safety implications. $J$ Hazard Mater 2016, 305, 87-95.

140. Singh, D.; Sotiriou, G. A.; Zhang, F.; Mead, J.; Bello, D.; Wohlleben, W.; Demokritou, P., End-of-life thermal decomposition of nano-enabled polymers: effect of nanofiller loading and polymer matrix on by-products. Environmental Science: Nano 2016, 3, (6), 1293-1305.

141. Sotiriou, G. A.; Singh, D.; Zhang, F.; Wohlleben, W.; Chalbot, M. G.; Kavouras, I. G.; Demokritou, P., An integrated methodology for the assessment of environmental health implications during thermal decomposition of nano-enabled products. Environ Sci Nano 2015, 2, (3), 262-272.

142. Goodwin, D. G.; Adeleye, A. S.; Sung, L.; Ho, K. T.; Burgess, R. M.; Petersen, E. J., Detection and Quantification of Graphene-Family Nanomaterials in the Environment. Environmental Science \& Technology 2018, 52, (8), 4491-4513.

143. Stueckle, T. A.; Davidson, D. C.; Derk, R.; Kornberg, T. G.; Battelli, L.; Friend, S.; Orandle, M.; Wagner, A.; Dinu, C. Z.; Sierros, K. A.; Agarwal, S.; Gupta, R. K.; Rojanasakul, Y.; Porter, D. W.; Rojanasakul, L., Short-Term Pulmonary Toxicity Assessment of Pre- and Post-incinerated Organomodified Nanoclay in Mice. ACS Nano 2018, 12, (3), 2292-2310.

144. Kruger, O.; Grabner, A.; Adam, C., Complete survey of German sewage sludge ash. Environ Sci Technol 2014, 48, (20), 11811-8.

145. Alva, A. K.; Syvertsen, J. P., Irrigation Water Salinity Affects Soil Nutrient Distribution, Root Density, and Leaf Nutrient Levels of Citrus under Drip Fertigation. Journal of Plant Nutrition 1991, 14, (7), 715-727.

146. Wijesekara, S. S.; Basnayake, B. F.; Vithanage, M., Organic-coated nanoparticulate zero valent iron for remediation of chemical oxygen demand (COD) and dissolved metals from tropical landfill leachate. Environ Sci Pollut Res Int 2014, 21, (11), 7075-87.

147. Yousuf, I., Methods for Estimation and Comparison of Activated Sludge Settleability. In 38th Annual WIOA QId Water Industry Operations Conference, Parklands, Gold Coast, 2013; pp 95-101.

148. 4500-O OXYGEN (DISSOLVED). In Standard Methods For the Examination of Water and Wastewater, Association, A. P. H., Ed. American Public Health Association, American Water Works Association: 2017.

149. EPA, U., Method 1686: Nitrate/Nitrite-N in Water and Biosolids by Manual Colorimetry. In US Environmental Protection Agency: Washington, DC, 2001; Vol. Method 1686.

150. EPA, U., Method 1690: Ammonia-N in Water and Biosolids by Automated Colorimetry with Preliminary Distillation. In US Environmental Protection Agency: Washington, DC, 2001; Vol. Method 1690.

151. Fytili, D.; Zabaniotou, A., Utilization of sewage sludge in EU application of old and new methods - A review. Renewable \& Sustainable Energy Reviews 2008, 12, (1), 116-140.

152. Gottschalk, F.; Sonderer, T.; Scholz, R. W.; Nowack, B., Modeled environmental concentrations of engineered nanomaterials ( $\mathrm{TiO}(2), \mathrm{ZnO}, \mathrm{Ag}, \mathrm{CNT}$, Fullerenes) for different regions. Environ Sci Technol 2009, 43, (24), 9216-22. 
153. Westerhoff, P.; Lee, S.; Yang, Y.; Gordon, G. W.; Hristovski, K.; Halden, R. U.; Herckes, P., Characterization, Recovery Opportunities, and Valuation of Metals in Municipal Sludges from US Wastewater Treatment Plants Nationwide. Environmental Science \& Technology 2015, 49, (16), 9479-9488.

154. Doolette, C. L.; McLaughlin, M. J.; Kirby, J. K.; Batstone, D. J.; Harris, H. H.; Ge, H.; Cornelis, G., Transformation of PVP coated silver nanoparticles in a simulated wastewater treatment process and the effect on microbial communities. Chem Cent J 2013, 7, (1), 46. 155. Limbach, L. K.; Bereiter, R.; Muller, E.; Krebs, R.; Galli, R.; Stark, W. J., Removal of oxide nanoparticles in a model wastewater treatment plant: influence of agglomeration and surfactants on clearing efficiency. Environ Sci Technol 2008, 42, (15), 5828-33.

156. Kaegi, R.; Voegelin, A.; Ort, C.; Sinnet, B.; Thalmann, B.; Krismer, J.; Hagendorfer, H.; Elumelu, M.; Mueller, E., Fate and transformation of silver nanoparticles in urban wastewater systems. Water Res 2013, 47, (12), 3866-77.

157. Westerhoff, P. K.; Kiser, M. A.; Hristovski, K., Nanomaterial removal and transformation during biological wastewater treatment. Environmental engineering science 2013, 30, (3), 109117.

158. Scott, J.; Beydoun, D.; Amal, R.; Low, G.; Cattle, J., Landfill management, leachate generation, and leach testing of solid wastes in Australia and overseas. Critical Reviews in Environmental Science and Technology 2005, 35, (3), 239-332.

159. Kjeldsen, P.; Barlaz, M. A.; Rooker, A. P.; Baun, A.; Ledin, A.; Christensen, T. H., Present and long-term composition of MSW landfill leachate: A review. Critical Reviews in Environmental Science and Technology 2002, 32, (4), 297-336.

160. El-Fadel, M.; Findikakis, A.; Leckie, J., Modeling leachate generation and transport in solid waste landfills. Environmental technology 1997, 18, (7), 669-686.

161. Froggett, S. J.; Clancy, S. F.; Boverhof, D. R.; Canady, R. A., A review and perspective of existing research on the release of nanomaterials from solid nanocomposites. Part Fibre Toxicol 2014, 11, (1), 17.

162. Mitrano, D. M.; Motellier, S.; Clavaguera, S.; Nowack, B., Review of nanomaterial aging and transformations through the life cycle of nano-enhanced products. Environ Int 2015, 77, 132-47.

163. Gonzalez-Galvez, D.; Janer, G.; Vilar, G.; Vilchez, A.; Vazquez-Campos, S., The Life Cycle of Engineered Nanoparticles. Adv Exp Med Biol 2017, 947, 41-69.

164. Foss Hansen, S.; Larsen, B. H.; Olsen, S. I.; Baun, A., Categorization framework to aid hazard identification of nanomaterials. Nanotoxicology 2007, 1, (3), 243-250.

165. Wohlleben, W.; Neubauer, N., Quantitative rates of release from weathered nanocomposites are determined across 5 orders of magnitude by the matrix, modulated by the embedded nanomaterial. Nanoimpact 2016, 1, 39-45.

166. Koivisto, A. J.; Jensen, A. C. O.; Kling, K. I.; Norgaard, A.; Brinch, A.; Christensen, F.; Jensen, K. A., Quantitative material releases from products and articles containing manufactured nanomaterials: Towards a release library. Nanoimpact 2017, 5, 119-132.

167. Al-Kattan, A.; Wichser, A.; Vonbank, R.; Brunner, S.; Ulrich, A.; Zuin, S.; Nowack, B., Release of TiO 2 from paints containing pigment-TiO 2 or nano-TiO 2 by weathering.

Environmental Science: Processes \& Impacts 2013, 15, (12), 2186-2193. 
168. Zuin, S.; Massari, A.; Ferrari, A.; Golanski, L., Formulation effects on the release of silica dioxide nanoparticles from paint debris to water. Sci Total Environ 2014, 476-477, 298-307.

169. Wohlleben, W.; Vilar, G.; Fernandez-Rosas, E.; Gonzalez-Galvez, D.; Gabriel, C.; Hirth, S.; Frechen, T.; Stanley, D.; Gorham, J.; Sung, L. P.; Hsueh, H. C.; Chuang, Y. F.; Nguyen, T.; VazquezCampos, S., A pilot interlaboratory comparison of protocols that simulate aging of nanocomposites and detect released fragments. Environmental Chemistry 2014, 11, (4), $402-$ 418.

170. Mitrano, D. M.; Limpiteeprakan, P.; Babel, S.; Nowack, B., Durability of nano-enhanced textiles through the life cycle: releases from landfilling after washing. Environmental ScienceNano 2016, 3, (2), 375-387.

171. Nowack, B.; Boldrin, A.; Caballero, A.; Hansen, S. F.; Gottschalk, F.; Heggelund, L.; Hennig, M.; Mackevica, A.; Maes, H.; Navratilova, J., Meeting the Needs for Released Nanomaterials Required for Further Testing? The SUN Approach. In ACS Publications: 2016.

172. Vílchez, A.; Fernández-Rosas, E.; González-Gálvez, D.; Vázquez-Campos, S., Nanomaterials Release from Nano-Enabled Products. In Indoor and Outdoor Nanoparticles, M, V., Ed. Springer: 2015; Vol. 48, pp 127-158.

173. Hischier, R.; Nowack, B.; Gottschalk, F.; Hincapie, I.; Steinfeldt, M.; Som, C., Life cycle assessment of façade coating systems containing manufactured nanomaterials. Journal of Nanoparticle Research 2015, 17, (2), 68.

174. Mitrano, D. M.; Rimmele, E.; Wichser, A.; Erni, R.; Height, M.; Nowack, B., Presence of nanoparticles in wash water from conventional silver and nano-silver textiles. ACS Nano 2014, 8, (7), 7208-19. 